\title{
Identification of optimal landforms to reduce impacts on the landscape using LiDAR for hosting a new highway
}

\author{
Manuel Loro, Rosa M. Arce, Emilio Ortega
}

\section{Landscape and road layout tracing}

1.

One of the key goals of new linear infrastructure planning and de-

sign (roads, railways, power lines, pipes and so on) when seeking to minimize environmental impact is to achieve better layouts that enable the reduction of ecological fragmentation and visual impacts in the landscape, among other aspects. Both the transport infrastructures and the extreme urban pressure are degrading rapidly the landscape diversity (Van Eetvelde and Antrop, 2009). Landscape change essentially affects the visual aspect of the landscape, and policy makers usually seek to limit this impact (Gobster et al., 2007).

Landscape has not been a relevant issue in the planning process for new infrastructure (Antonson, 2009; Arce et al., 2010; Loro et al., 2014). Then, improved knowledge of these aspects enables planners to locate areas for new infrastructures so as to cause less impact, reducing earthworks or the removal of objects with landscaping value, hiding the road from the view of residents, and preventing effects on wildlife corridors (Español et al., 2008; Tveit and Ode Sang, 2014). Nevertheless, once the highway layout has been defined, designers must adapt the infrastructure as the first step in integrating it into the landscape (Appleyard et al., 1964; Iuell et al., 2003). In this phase, the highway must now be seen as a means of contact with the landscape which can be enhanced by adapting its alignment, profile and cross sections, and even by creating visual barriers, planting or hydroseeding embankments (Español et al., 2008). While several road tracing guides have been published to solve this issue (see Table 1), there are few publications discussing how the recommendation regarding geomorphology, visibility and ecological landscape characteristics can be included in GIS during the route layout tracing phase (Atkinson et al., 2005; González et al., 2012; Ortega et al., 2016). One of the major challenges for planners is the early identification of certain landform typologies predominant in undulating valley areas or steep hillsides with changing shapes, which cause large cuttings and embankments and become a noticeable scar on the landscape (Español et al., 2008). It is also important to hide the infrastructure from external views and reduce the disturbance of landscapes with important ecological and visual quality.
Landforms can be defined as discrete morphological features composed by a common morphology of the land surface at a local scale (e.g. slope gradient, aspect and curvature), but also as a combination of several landform elements or smaller divisions of the land surface that have relatively constant morphometric properties at a regional scale (Pike et al., 2009). According to these authors, the definition process involves the following stages: (i) surface sampling (height measurements); (ii) surface generation (land-surface model); (iii) pre-processing (corrected land-surface model); and (iv) surface analysis.

In the case of surface sampling (i) and the land-surface model (ii), light detection and ranging (LiDAR) is effective for exploring targets with a three-dimensional structure due to its ability to acquire vertical information (Sasaki et al., 2012). The Digital Elevation Model (DEM) can then be obtained for the bare ground, and the Digital Surface Model (DSM) for the 3D features plus bare ground. The accuracy of these models is aligned with the most common scale used for new linear infrastructure planning and design (at least 1:5 K) beyond traditional thematic land-use maps (Arce et al., 2010; Loro et al., 2014). Various filtering methods can be applied to classify or separate raw LiDAR data into ground and non-ground data, although manual supervision is always required to filter the results, which are highly correlated to each case study (Liu, 2008). Once the DSM and DEM models are obtained, the new 3D geometry generated by road design software must be inserted as part of the pre-processing stage (iii). This allows the inclusion of standard cross and long profiles for roads, which are pre-defined in the mandatory technical specifications for the maximum and minimum length of straight sections or curve radii.

In the case of surface analysis (iv) related to DEM, the object delineation for certain land elements is challenging as it requires a semisupervised classification to detect shapes that comply with road-tracing recommendations in a study area subjected to a specific road geometry. This semi-supervised classification of landforms requires adjusting a large number of parameters and thresholds, considering characteristics of scale (e.g. relative position of a slope) and curvature (convexity and concavity at different planes) in the landscapes. A fuzzy rule set can be 
Table 1

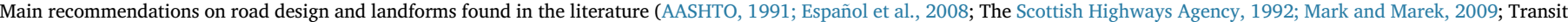
New Zealand, 2006; Valladares et al., 2011).

\begin{tabular}{|c|c|c|}
\hline Criteria & Recommended areas & Areas to avoid \\
\hline \multirow[t]{2}{*}{ Reduce the road presence in the landscape } & Larger areas (plains) & Tightest areas (narrow valleys) \\
\hline & $\begin{array}{l}\text { Lowest points on the landscape such as sides of valley bottoms and } \\
\text { upper edge of plains without steep slopes to reduce the impact on } \\
\text { highly productive soils and riparian forest. }\end{array}$ & Elevated sites in the layout in terms of landscape \\
\hline $\begin{array}{l}\text { Achieve lateral compensation in } \\
\text { earthworks }\end{array}$ & $\begin{array}{l}\text { Homogeneous middle hillside on both sides without very steep slopes. } \\
\text { Reduced ruggedness. }\end{array}$ & $\begin{array}{l}\text { Heterogeneous (rolling) hillside generating imbalances in } \\
\text { lateral compensation or large slopes (usually easily visible } \\
\text { from the valley) }\end{array}$ \\
\hline \multirow{2}{*}{$\begin{array}{l}\text { Achieve better adaptation to land surface } \\
\text { in the case of tracing in rugged areas }\end{array}$} & Curves could be traced in concave/convex areas. & ( \\
\hline & $\begin{array}{l}\text { Straight and level road sections may be short and located where the } \\
\text { terrain changes from concave to convex and vice versa. }\end{array}$ & \\
\hline Reduce visual and acoustic impact & $\begin{array}{l}\text { Open cutting when road layout is near urban areas and there is possible } \\
\text { land compensation along the longitudinal profile. }\end{array}$ & $\begin{array}{l}\text { Elevated sites in the layout near the location of urban } \\
\text { areas. }\end{array}$ \\
\hline $\begin{array}{l}\text { Adapt road embankments and cuttings to } \\
\text { terrain }\end{array}$ & $\begin{array}{l}\text { Design cross-section with no slope over } 2 \mathrm{H}: 1 \mathrm{~V} \text { for cuttings and fill } \\
\text { operations. In fill, } 3 \mathrm{H}: 2 \mathrm{~V} \text { is recommended if possible. }\end{array}$ & - \\
\hline
\end{tabular}

defined to combine landform parameters at different scales to obtain different land elements. This rule must be validated to state what type of curvature is the best descriptor to identify a particular landform (Schmidt and Hewitt, 2004).

GIS is also an interesting tool to perform visibility studies from DSM, showing whether an area can be seen or not by surrounding observers but also by drivers. Current GIS software packages now allow the calculation of the cumulative viewshed $(\mathrm{CV})$, or the number of times each location is visible from a set of viewpoints for each pixel (Chamberlain and Meitner, 2013). As a complement to $C V$ when calculating visual impacts, these authors suggest the need to include the amount of space occupied by an area in the landscape within an observer's view, as well as the relative distance to the observer and angle of vision (e.g. inside the car in road planning). The main disadvantage of mapping is that it cannot record people perceptions (psychological component of the landscape), and currently only partially complies with the concept of landscape defined in the European Landscape Convention (CE, 2000). As an alternative approach, some models have been developed to assess landscape quality based on mapping physical attributes (Dramstad et al., 2006; Martín et al., 2017; Vizzari, 2011; Wu et al., 2006), which can be considered sufficient for road planning optimization (Loro et al., 2014).

The main aim in the case of highways is to diminish the impact of this huge occupation of space and the conspicuous presence of this anthropic infrastructure on the landscape (Español et al., 2008). The current trend is to include both ecological (habitat patch structure and their interconnection by means of wildlife corridors) and visual aspects when defining landscape quality (internally also related to land forms and earth works). Both approaches use the same study scale (Russo et al., 2011) and dependence on landscape structure (Fry et al., 2009; Gobster et al., 2007; Llausàs and Nogué, 2012). In this sense, Oberholzer (2005) recommends a set of specific criteria for preventing the visual impact of highways: i) the landscape integrity ( $L I)$ or compatibility of the project with the qualities of the existing landscape; ii) the visibility of the project $(V P)$ based on distance from the project to selected viewpoints or vice versa; iii) the potential visual exposure of the area $(P V E)$ defined as the geographic area from which the project will be visible; and iv) the visual absorption capacity (VAC) of the landscape, defined as the potential of the landscape to conceal the proposed project based on screening by topography and vegetation.

Once these criteria have been evaluated, the optimum road layout can be obtained via a least-cost path analysis (LCPA) developed by Dijkstra (1959) and commonly included in GIS software. This algorithm is currently widely used in linear infrastructure planning to generate an accumulative cost surface on which to identify a line or corridor with similar cost (Atkinson et al., 2005; Bagli et al., 2010; González et al., 2012).
In response to the aforementioned concerns about the complexity of highway layout design under the various constraints, the aim of this study is to outline a methodology to determine and evaluate the integration of transport infrastructure layouts into the landscape. This integration is done by considering, using an innovative approach, the GIS- and LIDAR-based methods in the literature to assess the geomorphology, visibility and ecological characteristics of the landscape.

The structure of the paper is as follows. Section 2 describes the materials and methods used and it is divided into 4 subsections according to the main steps of the methodology. Results are presented in Section 3; and finally Section 4 contains the discussion of the results and some concluding remarks.

\section{Materials and methods}

Our approach (Fig. 1) addresses spatial road planning with a focus on the landscape in four stages. Stage I involved evaluating the landscape intended as the potential site for a new highway. Geomorphological, visual and ecological analyses were carried out after a surface analysis based on surface-model (DEM and DSM) indicators (e.g. landscape visual quality, visual exposure and land form classification). These two models and some other 3D objects (buildings, forest canopy and water surface) were previously produced using LiDAR data filtering methodologies.

Stage II is focused on the creation of a cost matrix from a combination of criteria on which subsequently to trace the highway layout. A model was developed in stage III to combine road tracing and GIS software outputs to create a realistic scenario with the new 3D highway geometry inserted in the DEM model. Finally, priority areas were located for corrective measures using visual indicators and the DSM model previously corrected in stage IV. The whole procedure is supported by a set of GIS models in ArcGIS 10.2 Model Builder to automate the analysis. Each GIS model delivers a specific product that is of potential use for road planning, as described below.

Our methodology was applied to the planning and design of a new highway ( $55 \mathrm{~km}$ in length) in a typical Mediterranean mosaic landscape in central Spain that will connect La Campiña (Guadalajara) and Sierra Norte (Madrid). The Spanish Highways Authority previously proposed several connecting corridor layout alternatives (see Fig. 2). The main challenge for this infrastructure is to comply with the recommendations of road tracing guides to avoid or reduce impacts on the landscape while considering the marked ruggedness of the terrain in the study area and the proximity of scattered populations along the new highway (potential surrounding observers). Several patches of forest are connected by wildlife corridors (Loro et al., 2015). Potential landscape impacts are expected from major road cuttings and embankments that disturb the aesthetic quality and the interception of wildlife corridors. 


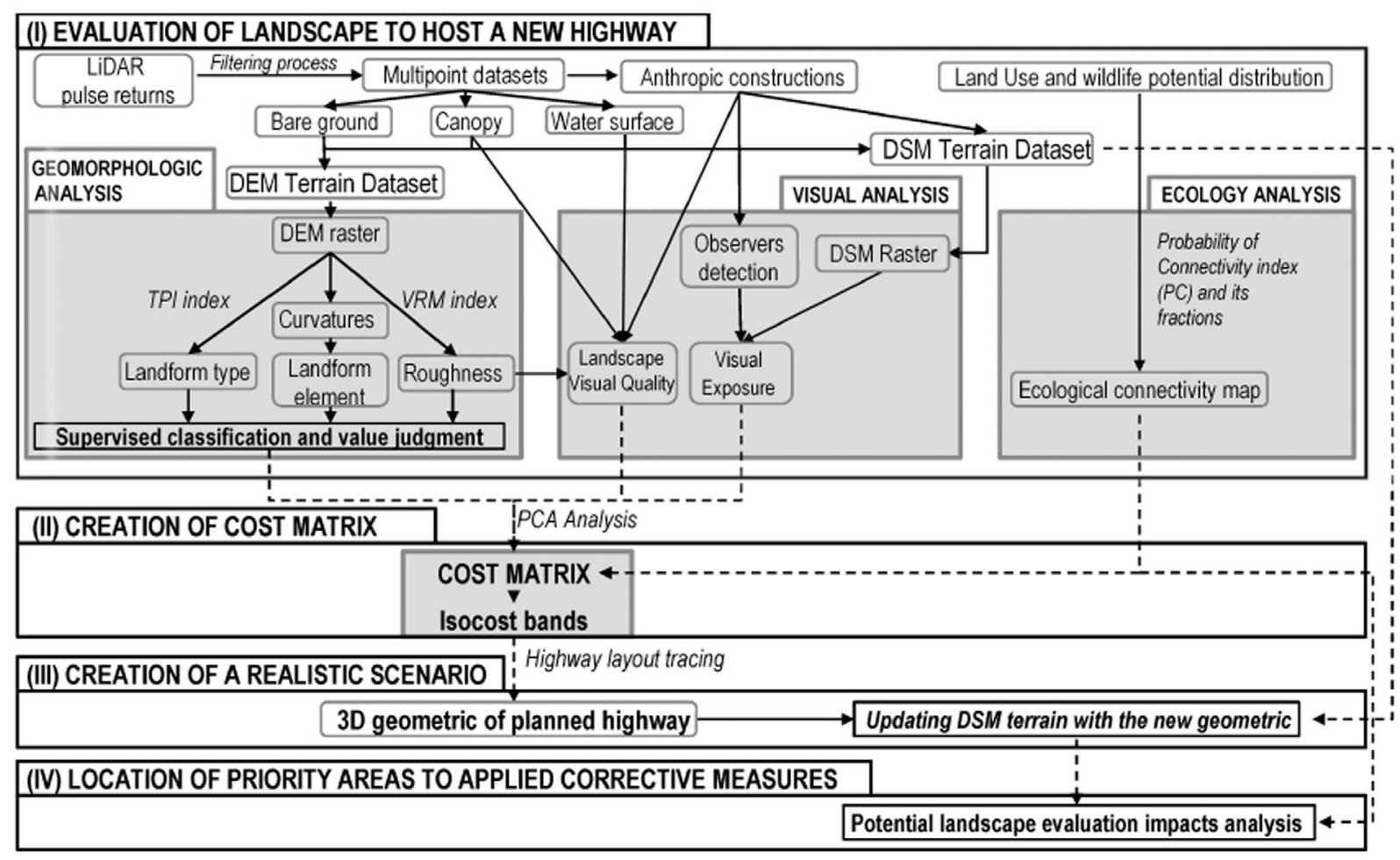

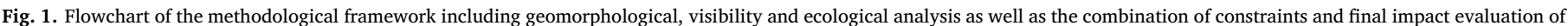
one defined highway layout.

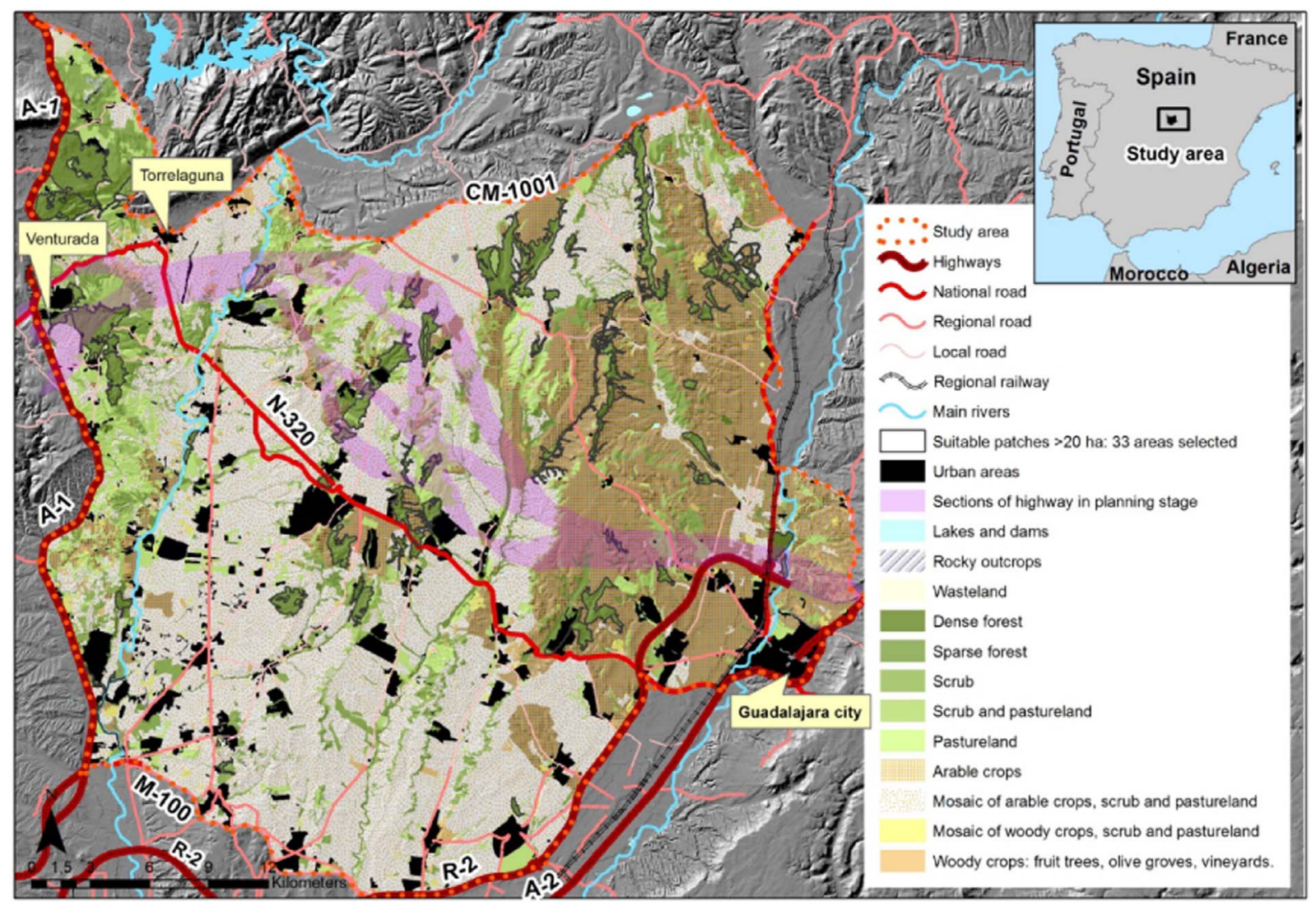

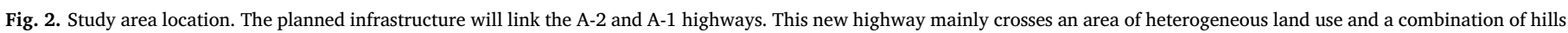
and broad plains. Several wildlife species are present in the study area (large mammals) which may be highly sensitive to the fragmentation of their ecosystems. 
The most common method in Spanish road construction projects is to establish different levels of hosting capacity for the study area. Values for territorial variables on thematic maps (physical, environmental, land-use and cultural) are grouped into a composite map considering the most restrictive scenario. Alternative corridor layouts are then traced and assessed. Landscape is a constraint factor that is rarely and poorly analyzed using quantitative methods, as opposed to qualitative methodologies based on expert judgment (Arce et al., 2010; Loro et al., 2014).

\subsection{Evaluation of landscape to host a new highway}

This evaluation is developed following a number of steps. First, the LIDAR dataset is processed as the basic data for the next analysis. Then, a geomorphological, a visual and an ecological landscape GIS-based analysis are done.

\subsubsection{Pre-processing of the Lidar dataset}

The LiDAR dataset was converted to multipoint and single point feature classes of 3D mass points according to the standardized filter class code and return values, separating them into unique feature classes: canopy surface (upper, mid and low canopy), ground, water surfaces and anthropic constructions. In the case of anthropic constructions, GPS recording time was also included in the multipoint feature class output to define different building footprints.

DEM and DSM raster grids were generated from multipoint datasets. Two terrain datasets were processed with the ArcGIS build terrain tool. A terrain dataset is a multi-resolution, TIN-based surface (triangulated irregular network) built from measurements stored as features (multipoint, lines and polygons) in a geodatabase (Childs, 2011). The DSM terrain was updated before and after the design of the new highway in order to evaluate its visual impact on the landscape (Section 2.1.3).

\subsubsection{Geomorphological analysis}

The geomorphological analysis was performed separately to calculate landform elements and types in the study area.

2.1.2.1. Landform elements. Landform elements were sorted into 15 classes following Schmidt and Hewitt's (2004) automated classification, which is a combination of 9 classes proposed by Dikau (1989) for sloping areas and 6 classes proposed by Wood (1996) for flat areas. These elements must first be sorted into sloping and flat elements and subsequently grouped based on curvatures (convex, concave and straight) according to signs of tangential and profile curvatures for sloping areas, and maximum and minimum curvatures for flat areas (see Table 2). In our study area, we conducted an iteration process to redefine the threshold values that best fit AASHTO regulations for geometric highway design.

The basic land-surface parameter - or LSP (slope gradient and curvatures) - was computed within a $3 \times 3$ filter window analysis (see Table 3). A filter window analysis examines the relationship between one pixel (target pixel or central pixel of the core) and its neighbourhood pixel elevation values (Evans, 1979; Olaya, 2009). Statistical LSP was also calculated using the Vector Ruggedness Measure -VRM(Sappington et al., 2007). According to the authors, high values of VRM indicate that the terrain is rather irregular around the pixel being analyzed, while low ones denote a smooth terrain.

The form classification was defined with fuzzy boundaries according to a simple linear membership function with two thresholds (slope gradient and curvature) in a range of $0-1$, following the authors' proposed methodology (Burrough, 1989; Schmidt and Hewitt, 2004). In our case, an iteration process was needed to set the threshold values that best fit AASHTO regulations (AASHTO, 2004) and the recommendations of road design manuals (see Table 1 and Table 2). Aerial photos of existing highways and prior identified landforms (e.g. road embankments and cuttings whose geometry is defined by road building regulations) were used to supervise our rules for classifying terrain entities and defining these thresholds.

Finally, the 15 maps of each fuzzy form element were ranked to obtain the highest membership function and thereby define the predominant form element class for each pixel, as suggested by Schmidt and Hewitt (2004). Each form element was then assessed by value judgments based on the recommendations in Table 1. In total, 10 out of 15 categories were found in our study area (see Fig. 3).

2.1.2.2. Landform types. Landform types were defined by the morphometric properties of the whole set of pixels. DEM pixels were classified according to the Topographic Position Index (TPI) following Weiss's methodology (Weiss, 2000), which classifies the terrain according to slope gradient (in degrees) and the TPI index defined by its traditional TPI or its $T P I_{S E}$ standardized elevation formulas:

$T P I=Z_{\text {focal }}-\bar{Z}_{\text {neighborhood }}$

$T P I_{S E}=\frac{\mathrm{Z}_{\text {focal }}-\overline{\mathrm{Z}}_{\text {neighborhood }}}{\mathrm{SD}_{\text {neighborhood }}}$

Where $Z_{\text {focal }}$ is the elevation of the target pixel, $\bar{Z}_{\text {neighborhood }}$ is the average elevation of all pixels in the neighbourhood, and $S D_{\text {neighborhood }}$ is the neighbourhood Standard Deviation of elevation values. Both indexes were calculated for DEM with the Land Facet Corridors tool (Jenness et al., 2011) using a search radius of $30 \mathrm{~m}$ and 12 degrees of slope as threshold values. We chose these values to detect valleys and hills that were wide and steep enough to satisfy the technical criteria of minimum highway standard section and profile. In total, six categories were defined and later assessed by value judgments based on the recommendations in Table 1 . The partial results are shown in Fig. 4 and Table 3.

\subsubsection{Visual landscape analysis}

The visual landscape analysis is performed following Oberholzer's (2005) recommendations and we studied the i) landscape integrity ( $L I$ ); ii) the visibility of the project $(V P)$; iii) the potential visual exposure of the area $(P V E)$; and iv) the visual absorption capacity (VAC) of the landscape.

We calculated landscape integrity $(L I)$ as the inverse of Landscape Visual Potential Quality $\left(L Q_{p}\right)$, in view of the fact that a new highway would have a higher visual impact on potential observers outside the highway (Stucky et al., 1998). $L Q_{p}$ was calculated by a mapping measurement methodology based on landscape physical attributes. The physical attributes were described based on the density (but also the variety) of the elements of value existing within a specific context, and on the quality level associated with those elements (see Table 4). The influence of distance to these objects (rivers, canopy and single building points) was studied with GIS gridding techniques such as kernel density estimation (KDE), as proposed by Vizzari (2011). KDE produces raster surfaces surrounding each point or line according to a quadratic formula, with the highest value at the centre of the object's position. $K D E$ analysis requires the definition of the search radius and the local quantitative value ( $L Q V$ ) of each component with an influence on the $L Q_{p}$ (see Table 4). The landform diversity $(L D)$ component was directly defined by the VRM index from the DEM raster instead of with KDE methodology.

In order to combine the selected indexes, all values were previously standardized to a common range of $0-1$ by the interval standardization method (Malczewski, 1999). A continuous $L Q_{p}$ relative to the study area was calculated as the sum of the relative importance of each naturalistic and physical landscape component, as follows:

$L Q_{p}=(\bar{W}+\overline{L D}+\bar{D} \times \overline{C C}-\bar{U})$

Where $\bar{W}$ is the normalized water component weighted by the slope of the river bed, $\overline{L D}$ is the normalized landform component calculated by the VRM index, $\bar{D}$ is the normalized diversity component weighted by 
Table 2

Classification of landform elements in the study area. Source: modified from Schmidt and Hewitt (2004). Reproduced with permission.

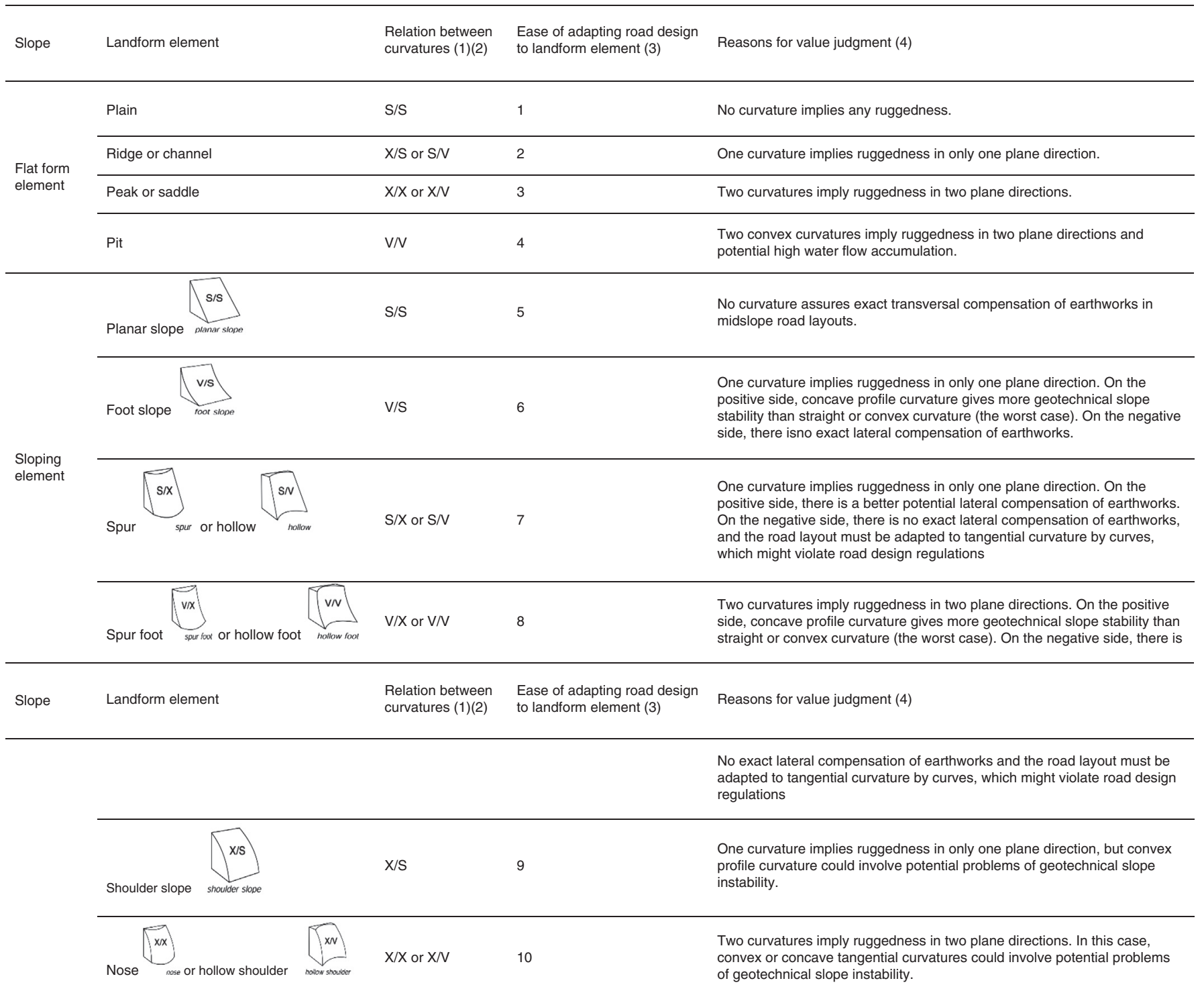

Where:

(1) In slope areas, the relation of values of profile and tangential curvatures (P/T) can be convex (X), straight (S) or concave (V), according to formulas proposed by Shary (1995) for profile curvature, and by Evans (1979) for tangential curvature. Both curvatures were calculated by model builder scripting and the DEM surface analysis tool (Jenness, 2011).

(2) In flat areas, minimum and maximum curvature values (m/M) can be convex (X), straight (S) or concave (V), according to formulas proposed by Sehary (1995).

(3) Scale from $1=$ easiest, to $10=$ worst.

(4) More ruggedness implies a greater potential for earthworks and visual impact.

the density of vegetation points (output of the previous LiDAR filtering process) or biomass value obtained by kernel density operation of canopy multipoint dataset (search radius $5 \mathrm{~m}$ ) (see Fig. 5), $\overline{C C}$ is the normalized canopy cover component weighted by the tree height, and
$\bar{U}$ is the normalized anthropic component weighted by the building height and area occupied. Partial and final maps are shown in Fig. 6.

For the VP criterion, each pixel in the study area was weighted by its distance from potential observers (limited to $5 \mathrm{~km}$ as a general

Table 3

Landform types based on the Topographic Position Index defined by standardized elevation $T P I_{S E}$.

\begin{tabular}{|c|c|c|}
\hline Landform type & Ease of adapting road design to landform type (1) & Reasons for value judgment (2) \\
\hline Gentle slopes & 1 & Lowest points on the landscape such as sides of valley bottoms or upper edge of plains \\
\hline Lower slopes & 2 & Second lowest points on the landscape. \\
\hline Steep slopes & 3 & High potential for unbalanced earthworks and slope stability. \\
\hline Upper slopes & 4 & The road has a dominant presence in the landscape. \\
\hline Valleys & 5 & Avoid valleys as they contain highly productive soils and riparian forest. \\
\hline Ridges & 6 & Land elements defined by extreme ruggedness and an elevated position in the landscape. \\
\hline
\end{tabular}

Scale from 1 (the easiest) to 10 (the worst), based on Table 1 showing collected best practices in road layout design. 


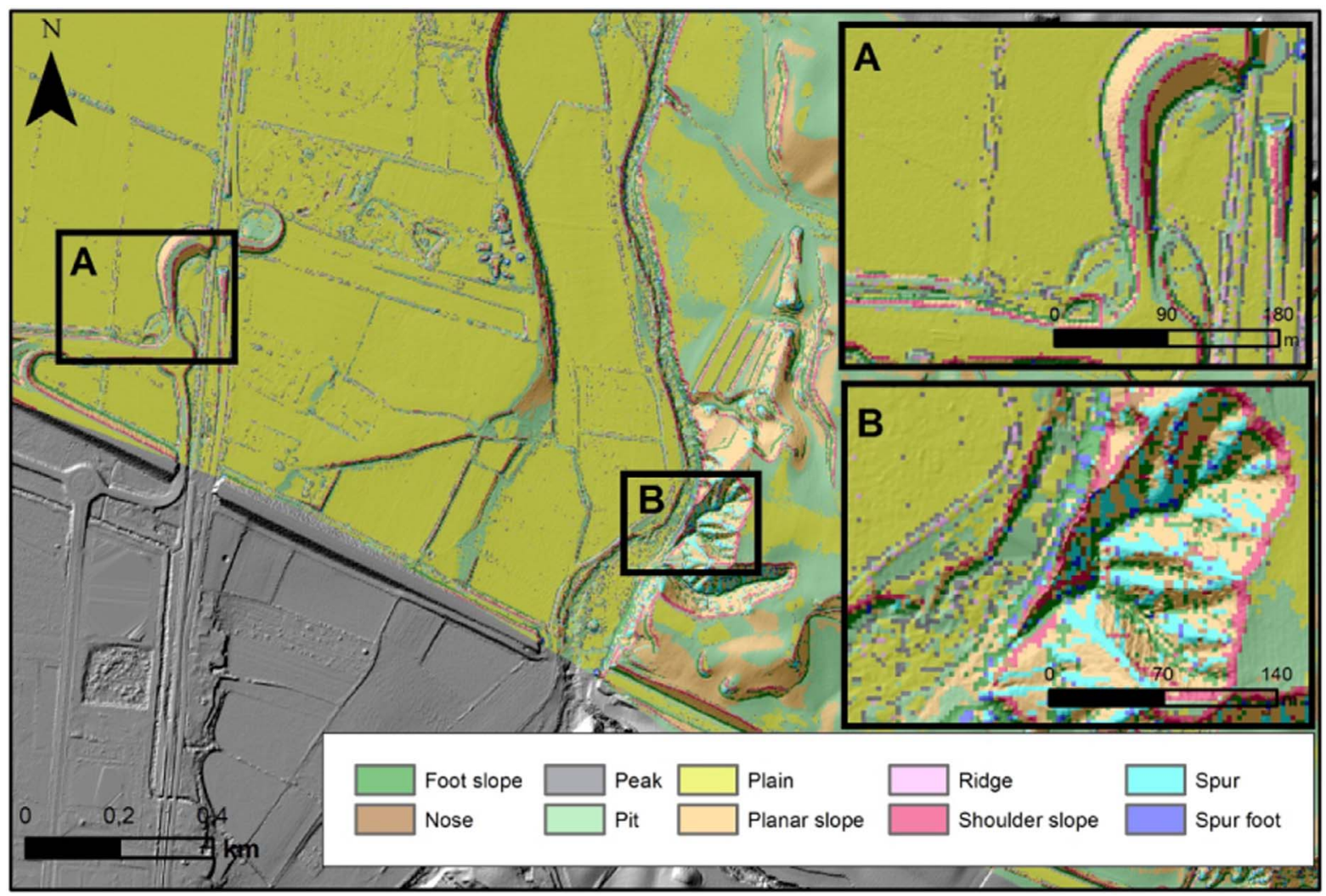

Fig. 3. Landform elements in our study area according to Schmidt and Hewitt's (2004) semi-supervised classification.

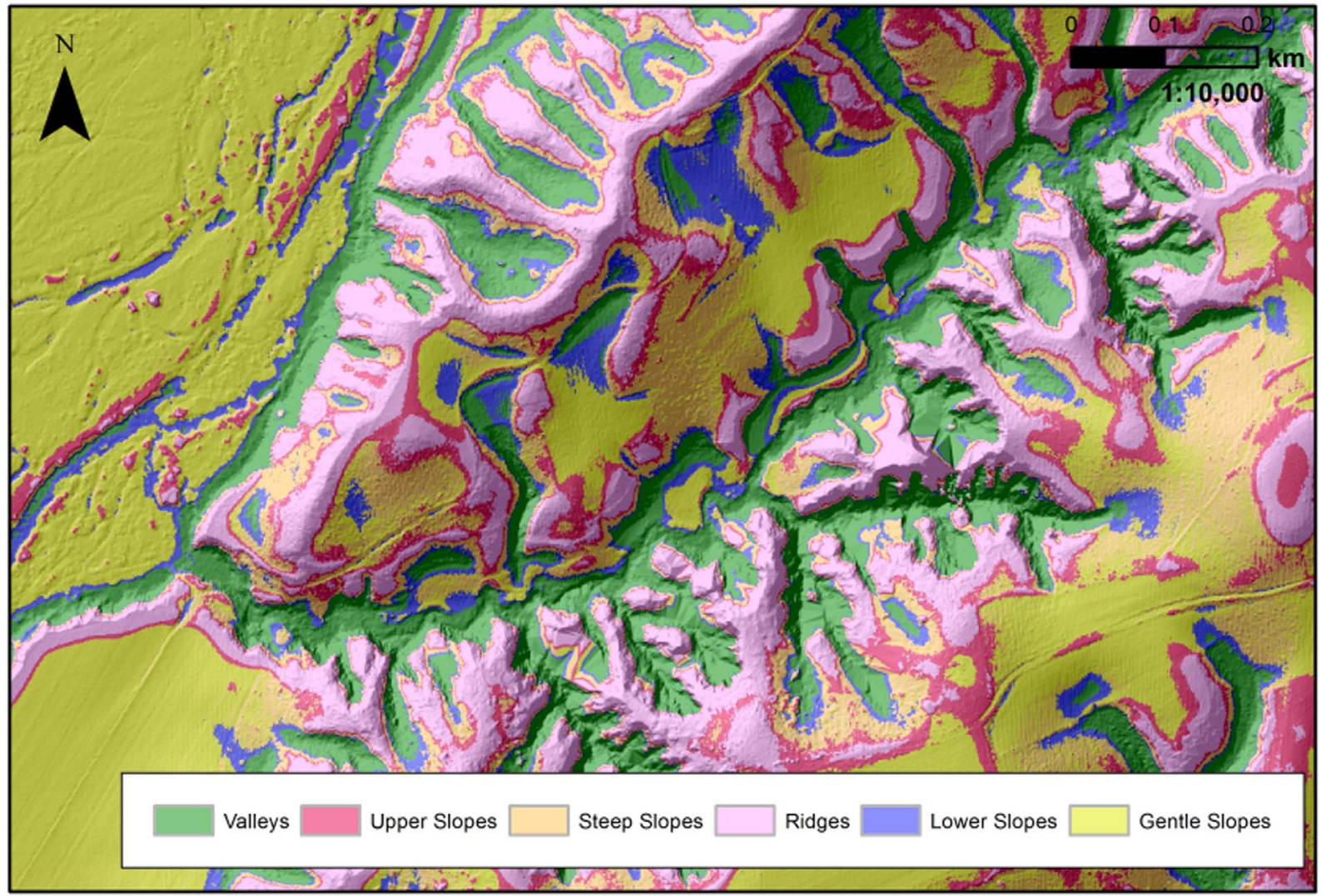

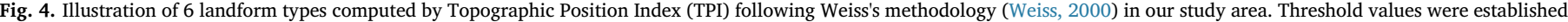
within a search radius of $30 \mathrm{~m}$ and 12 degrees of slope. 
panoramic view reference value) by the Euclidean distance tool. This was done to correct the visibility analysis and the effect of the noise of higher impacts from highway layouts closer to observers.

Potential visual exposure (PVE) and the Visual Absorption Capacity $(V A C)$ criteria were added; as the DSM includes topography and vegetation (see Section 2.1.1 above) and we assumed that vegetation (trees and shrubs) were dense enough to be impenetrable by sight. We also improved the calculation by including the cumulative viewshed $(\mathrm{CV})$ for each pixel in the study area -the number of times that pixel can be seen by each observer located in 5-km radius (considered as the value of the panoramic view by Cañas et al., 2009)-, and defined this criteria as Visual Exposure (VE). Another improvement was a more precise definition of observer point locations. Instead of using the coarser delimitation of houses provided by thematic land use maps -SIOSE, with a scale of 1:25 K (Ministerio de Fomento, 2005)-, we developed a GIS routine to define these observation points from the buildings multipoint previously extracted from the LiDAR dataset, which was defined as the Buildings Delimitation from LiDAR (BDL) model.

The first step of the BDL methodology is to aggregate the anthropic construction multipoint dataset into different subsets according to a threshold proximate distance between them (in our case $3 \mathrm{~m}$ ) and GPS recording time. This process consists of grouping points belonging to the same building into the same set to obtain a perimeter polygon (aggregate point tool). Also, real building layouts were corrected by estimating the minimum bounding geometry defined by the rectangle of the smallest width enclosing each feature (Fig. 7).

Once the observation points were defined, the Cumulative Viewshed $(\mathrm{CV})$ was analyzed based on pixels that are most often visible by different potential observers $\left(C V_{0}\right)$. Other visual exposure maps $\left(\mathrm{CV}_{2}\right.$ and $\mathrm{CV}_{4}$ ) were calculated, varying the pixel $\mathrm{z}$ elevation of the input observation points from 2 (such as car height) to $4 \mathrm{~m}$ (truck height).

Finally, Global VA criterion was calculated from the aggregation of homogenized values to a common scale $(0-1)$ by the interval standardization method:

$V A=\overline{L Q p} \cdot \overline{V P} \cdot \overline{C V} m$

Where $\overline{L Q p}$ is the normalized potential landscape quality $L Q_{p}, \overline{V P}$ is the normalized Visibility of the Project $(V P)$-where higher values are given the closer the pixel is to the observer location-, and $\overline{C V} m$ is the average value of normalized visual exposure or the cumulative values of views of $\overline{C V_{0}}, \overline{C V}_{2}$ and $\overline{C V}_{4}$. Partial and final maps of this analysis are shown in Fig. 8.

\subsubsection{Landscape ecology analysis}

We used an ecological connectivity map -developed by Loro et al. (2015)-, where each pixel in the study area is quantified through the level of connection provided by the sum of the overlapped wildlife corridors. These elements are divided into 528 wildlife corridors (or links) and 33 habitat patches (or nodes) and represent a graph-based approach to landscape ecological connectivity which can be studied through the Probability of Connectivity index $(P C)$ described by Saura and Pascual-Hortal (2007) and its fractions (Saura and Rubio, 2010) (see Fig. 9).

\subsection{Creation of the cost matrix}

The cost matrix was developed in three steps. As the selected constraint criteria (geomorphology, visual and ecological) have different scales (discrete and continuous scales), the first step was to apply a fuzzy linear transformation function (ArcGIS 10.2. fuzzy membership tool) to transform them into a common ratio scale (0-1).

In the second step, a Principal Components Analysis (PCA) was performed to detect redundancy or collinearity among the criteria (using the ArcGIS PAC multivariate tool), which showed that the VRA index was not required to explain the landform constraint criterion due to the low rate of covariance (coefficient of correlation, $r=0.99$ ) with 


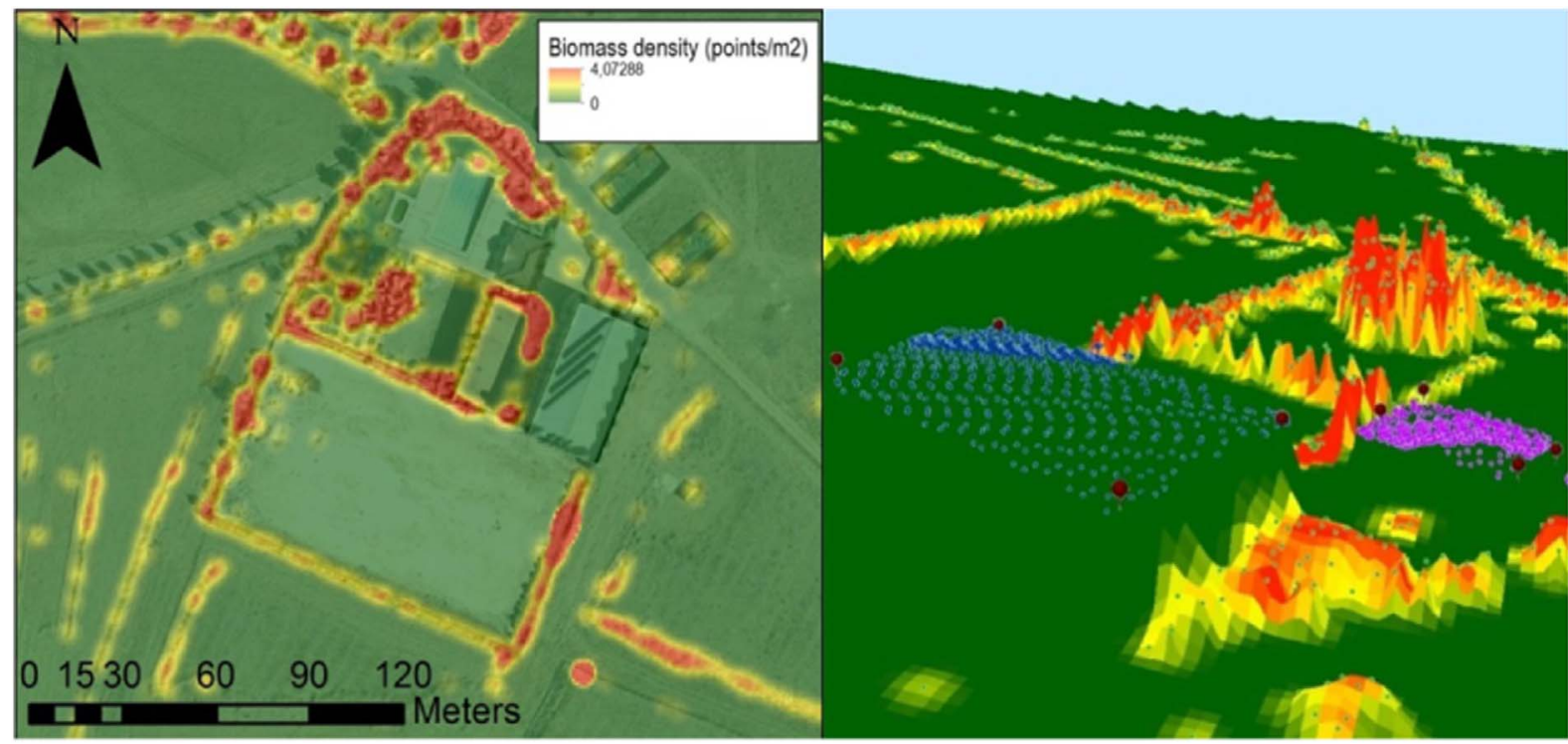

Fig. 5. Biomass density raster (left) obtained by kernel density operation of canopy multipoint dataset (search radius $5 \mathrm{~m}$ ) and the $3 \mathrm{D}$ visualization (right).

the rest of the combined criteria.

In the third step, the homogenized criteria were aggregated using a fuzzy operator OR (maximum value of the rank of values in each pixel of the study area), giving an overall index of potential carrying capacity to trace a new highway layout or cost matrix. We chose this fuzzy operator according to Spanish highway planning regulations (Loro et al., 2014) which suggest setting the most restrictive value found for each pixel in the study area for each evaluation criterion.

Finally, we performed a GIS accumulative cost distance function between the origin and destination to calculate isocost bands or bands delimited with a similar cost range. These bands were calculated only inside the predefined highway corridors, thus allowing bottlenecks to be displayed depending on the selected threshold value. An iterative process was conducted by modifying threshold values, defined by Natural Breaks (Jenks, 1967), until alternatives were found without bottlenecks and with a limited minimum width of $30 \mathrm{~m}$ (the standard size of a regular highway section in Spain is $20 \mathrm{~m}$ ) following the methodology proposed by Loro et al. (2015).

\subsection{Creation of a realistic scenario}

The final layout was traced following AASHTO highway design standards (AASHTO, 2004) with AutoCAD Civil 3D software based on previously calculated isocost bands as a reference. In this process, the layout was locally traced outside of these isocost bands in accordance with geometric highway design standards.

Finally, the DSM terrain calculated in Section 2.1.1 was updated with the new 3D geometry of the highway, and defined as $\mathrm{DSM}_{\mathrm{h}}$. This process involved converting the $3 \mathrm{D}$ lines generated with the CAD software into a polygon and then using this to erase the multipoint dataset contained within the polygons. A new terrain was then generated following the process described in Section 2.1.1, in this case including the new 3D highway geometry lines -as "hard replace" break lines- and adding the DEM multipoint dataset without the erased points (see Fig. 10-A). Finally, a new DEM raster was extracted from the modified terrain which included the new infrastructure (ArcGIS 10.2 terrain to raster tool, window size and ZMIN thinning methodology) (see Fig. 10).

\subsection{Location of priority areas to apply corrective measures}

Using the new $\mathrm{DSM}_{\mathrm{h}}$ as input, two evaluation indexes were defined to assess the landscape impact in order to propose corrective measures.
The index for estimating the visual impact on the landscape (IA) for each one-kilometer highway section was calculated following the equation:

$I A_{k m}=\sum\left(\overline{H E C} \cdot \overline{V A}_{h} \cdot 100\right)_{k m}$

Where $\overline{H E C}$ is the normalized (0-1) maximum height in each embankment or cutting, and $\overline{V A}_{h}$ is the $\overline{V A}$ calculated for the $\mathrm{DSM}_{\mathrm{h}}$ excluding the closest landscape elements corresponding to road elements (see Section 2.1.3 and Fig. 10).

The index for estimating the impact on the landscape ecology component $\left(L A E_{k m}\right)$ for each one-kilometer highway section was calculated following the equation:

$L A E_{k m}=\sum\left(\overline{C_{k}} \cdot l_{k, k m}\right)_{k m}$

Where $\overline{C_{k}}$ is the connectivity value provided by link $k$ (as a percentage) for the overall connectivity provided by all the links in the study area (regardless of whether they are affected by the highway), which was $23.48 \% ; l_{k, k m}$ is the length of the segment of link $k$ intersected by the highway in the one-kilometer section. Only complete intersected links for each highway were taken into account to calculate the index.

The study area around the highway was also characterized in terms of its visibility by users and the scenic quality of its landscape background. The index of the scenic potential of highway sections (SHS) was calculated following the equation:

$S H S=\overline{L Q p}_{b} \cdot \overline{C V}_{h, 100}$

Where $\overline{L Q p}_{b}$ is the normalized $L Q_{p}$ of landscape units located in the scenic background (Fig. 11-C), excluding nearby highway components (cuttings and embankments or road carriageway), and $\overline{C V}_{h, 100}$ is the normalized cumulative viewshed $(\mathrm{CV})$ or frequency of views by the planned highway users every $100 \mathrm{~m}$ (Fig. 11-D).

This calculation was made by defining observation points every $100 \mathrm{~m}$ in each lane direction (right and left lane) of the highway based on angle changes in the layout with the azimuth (see Fig. 11-A). Following the recommendations of previous studies (Glaría and Ceñal, 1993; Ministerio de Fomento - Esteyco, 1999), the assessment parameters were defined to simulate the actual position of the potential observers inside a car: $1.1 \mathrm{~m}$ for the driver's eye height above the road surface, $2 \mathrm{~m}$ for the driver's distance from the highway centerline, 180 horizontal degrees (which includes driver and passengers) and 45 and - 15 vertical degrees for the trajectory of potential visibility from the car front window for $100 \mathrm{~km} / \mathrm{h}$ speed, and two 


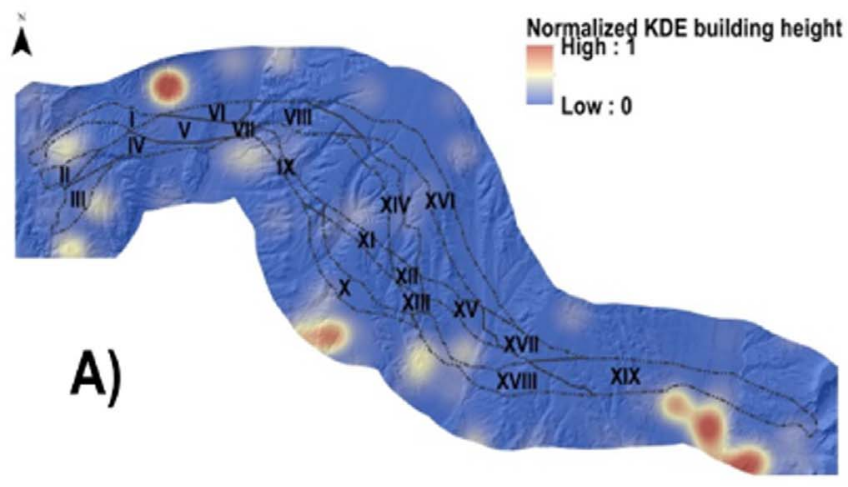

I... Sections of alternative highway corridors
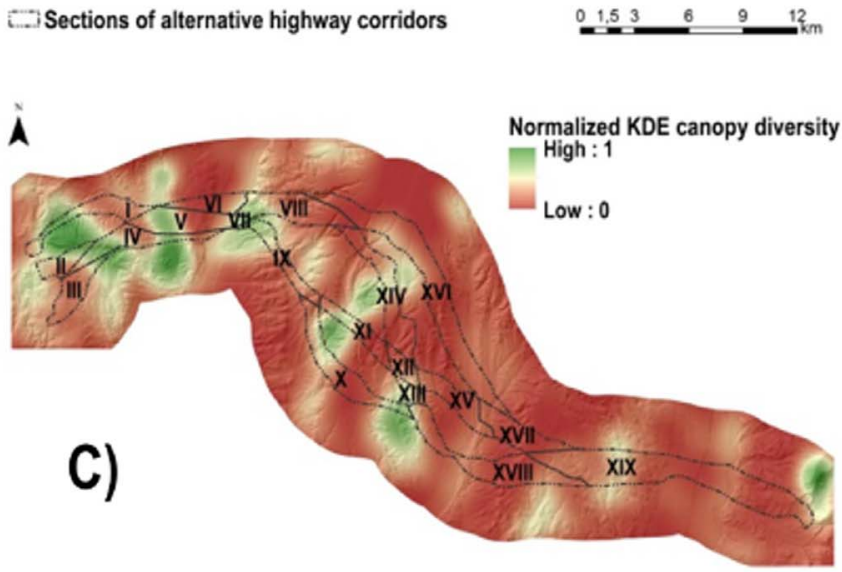

Sections of alternative highway corridors
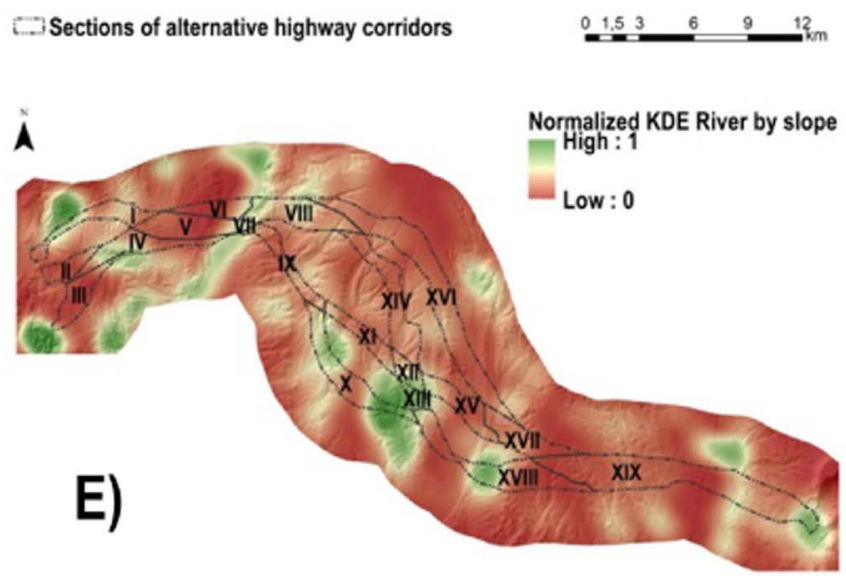

sections of alternative highway corridors

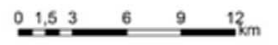

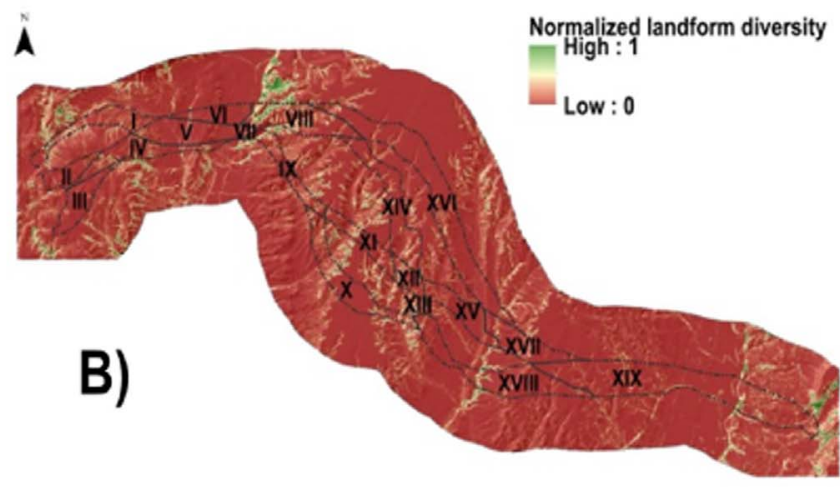

cs.Sections of alternative highway corridors
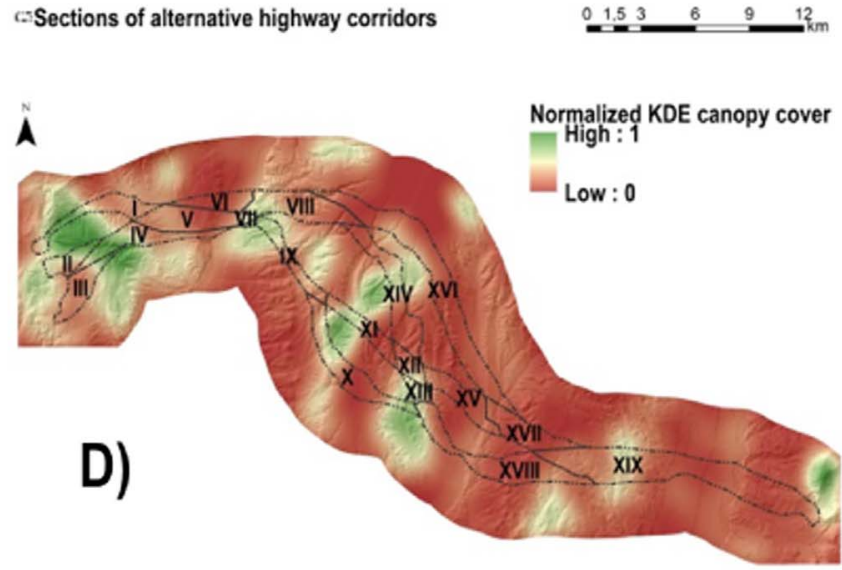

Sections of alternative highway corridors
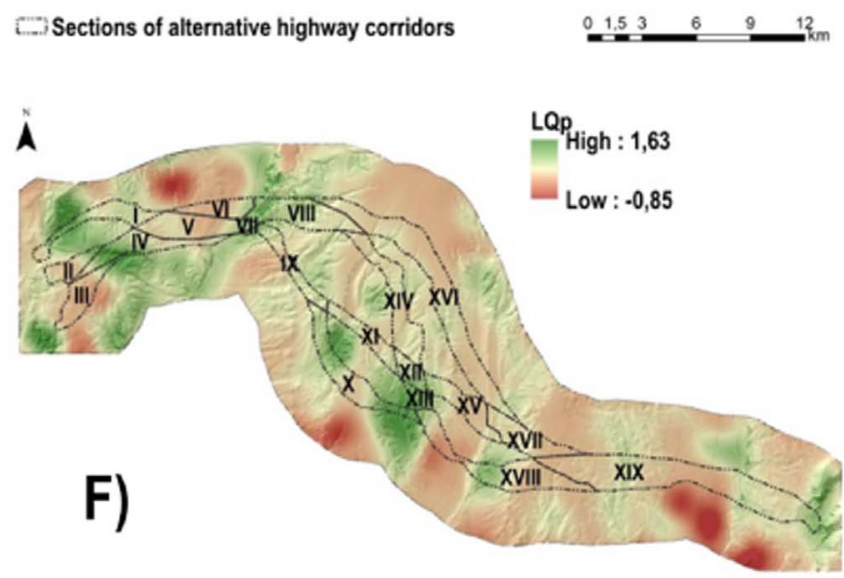

C... Sections of alternative highway corridors

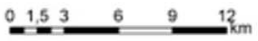

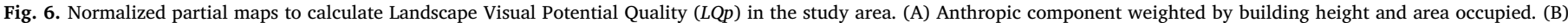

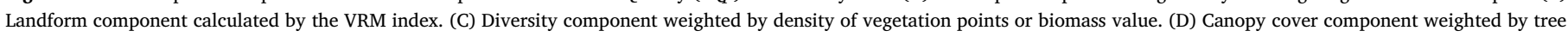
height. (E) Water component weighted by slope of river bed. (f) Potential visual landscape quality map ( $L Q p$ ) generated with Eq. 3.

search radius of potential visibility $(600 \mathrm{~m}$ for clear vision and $1500 \mathrm{~m}$ for long vision). The azimuth angle of each highway stretch was previously calculated to define the start and end angles of the horizontal scan range for each lane direction in the visibility analysis.

\section{Results}

The lowest cost values of isocost bands were obtained in the centre of the study area (section XVI, up to $29 \%$ less cost than nearby sections), and on the western edge (section II, up to $31 \%$ less accumulative cost) (see Fig. 12). On the eastern edge, section XIX also had low cost values due to low values of $L A E, V A$ and $L A U$ (less than $0.5 \%$ ).
In contrast, sections XI-XII and XV have a higher rate of impact on wildlife corridors (up to 9\%). Other sections such as X and XIV have a combination with a loss effect for all the variables. Higher $V A$ values are concentrated in sections V, VI and XVIII (Fig. 8-D), but their relative importance to other variables is fairly small $(2-4 \%$ of relative cost value). $L A E$ values are also significant in all sections with a relative cost value of $70-90 \%$, especially in sections IX and X.

The inclusion of a minimum isocost bandwidth shows that the least cost path is discarded in section XX (Fig. 12-A), while in other sections the least cost path is in the centre of one of the branches of the isocost band (Fig. 12-B). It should be noted that these isocost bands are intended as a guide only for the final highway layout tracing phase with 


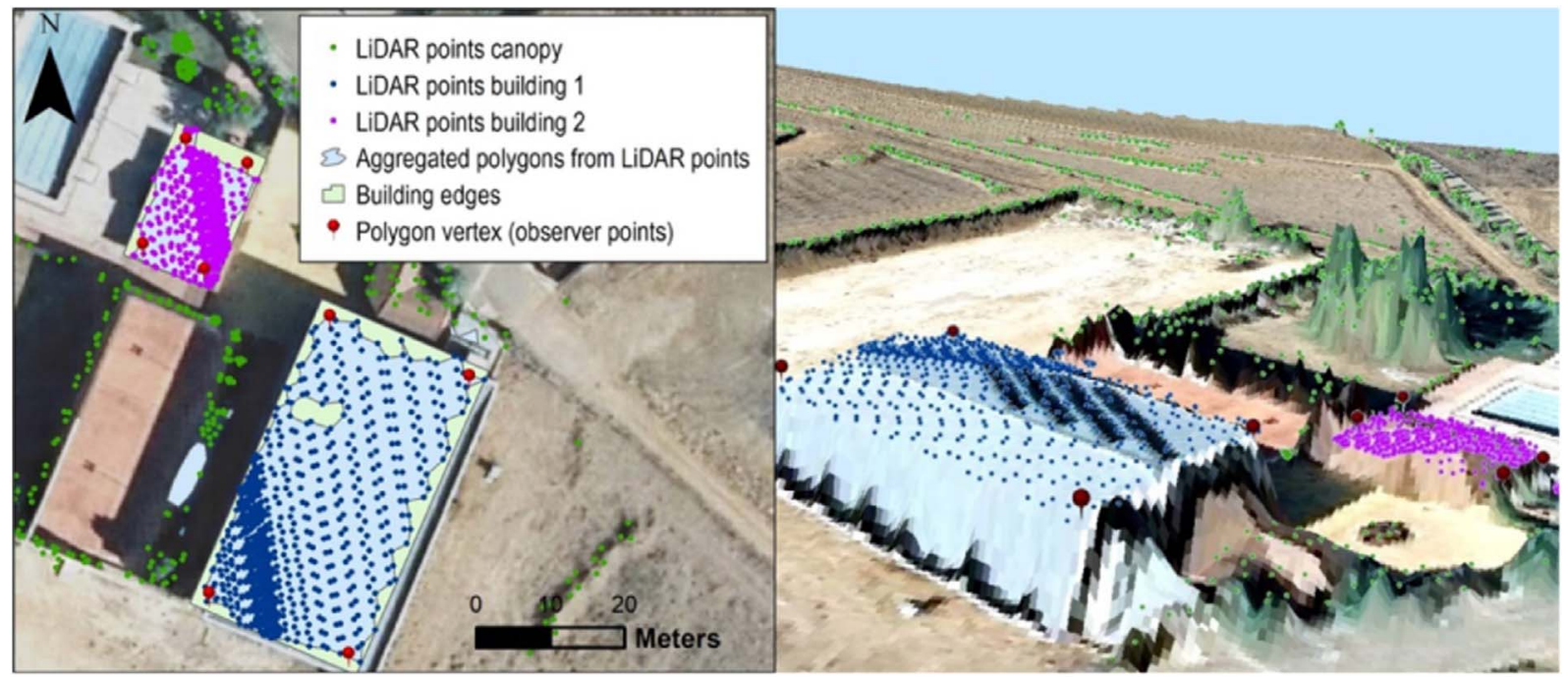

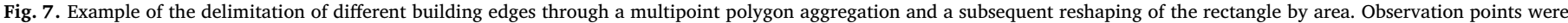
located inside the delimited buildings for the visibility analysis.

AutoCAD Civil 3D. As can be seen in Fig. 12-B, in section XVI we were unable to trace a layout within the isocost band due to limitations in the geometric design of the curve radius and length of straight highway stretches.

Impact indicators such as higher $I A_{k m}$ values are concentrated in sections 42 and 43 due to high density of potential observers ( $C V$ index) near the new highway (VP index). These observers can also see embankments with an average height of 10-15 m (HEC index) with attractive landscape as background scenery ( $L Q_{p}$ index) (see Fig. 14). It should be noted that these highway sections are located in an area where isocost bands present a high rate of bottlenecks and where there is no corridor alternative (Fig. 13, section VI).

Although section 33 and 39 show high rates for most of the indexes, this is due to the fact that they are inflexion points for the $C V$ and $I A_{k m}$

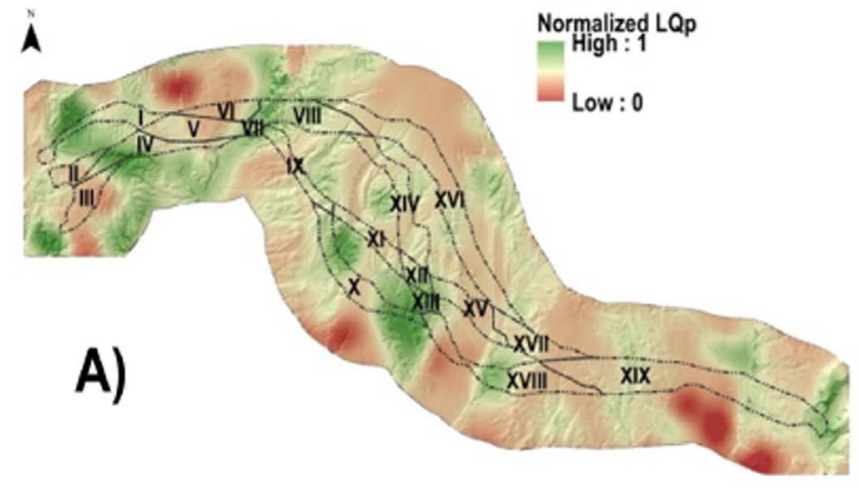

Sections of alternative highway corridors
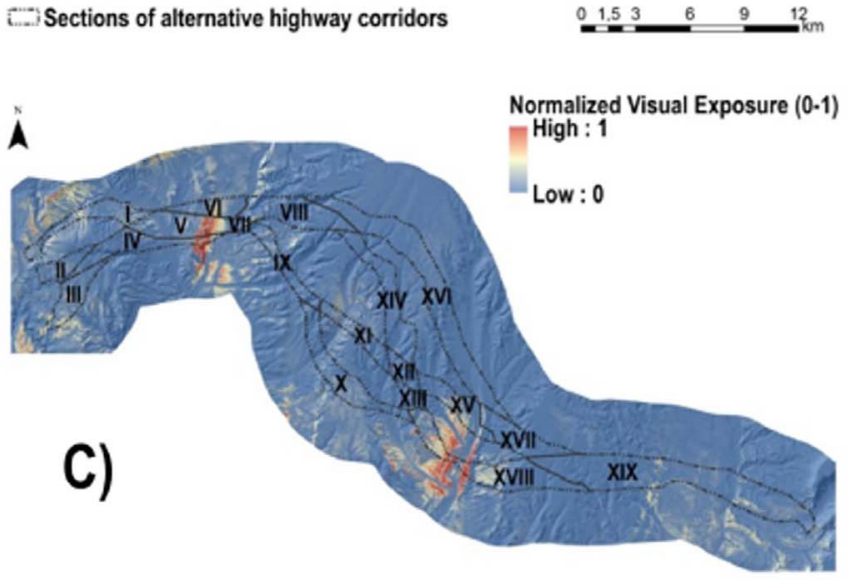

C.... Sections of alternative highway corridors

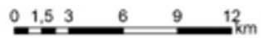

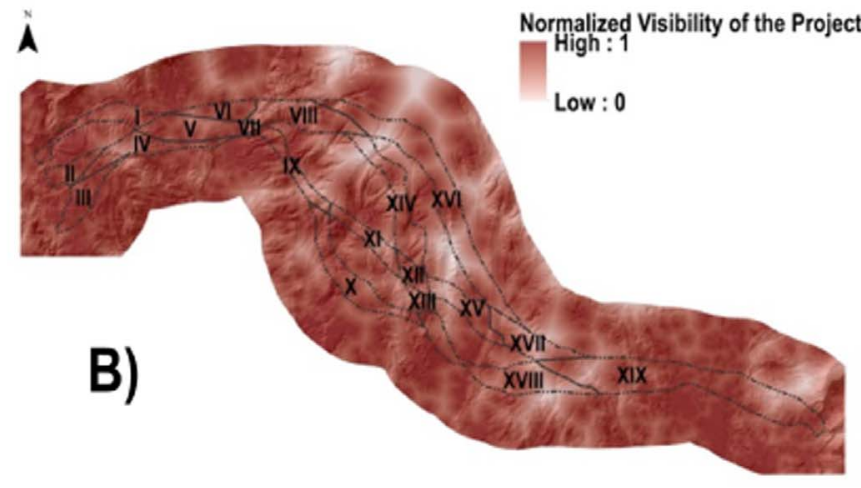

E.:-.) Sections of alternative highway corridors

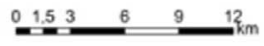

$\hat{A}$
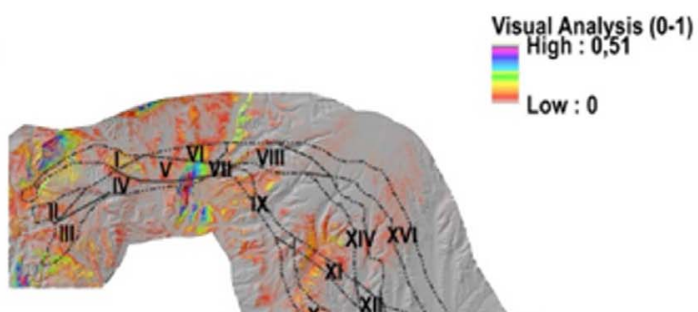

D)

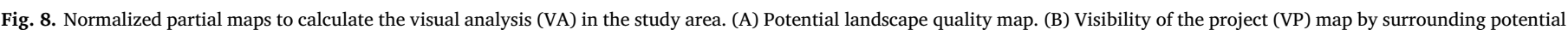
observers. (C) Average value of visual exposure or cumulative view map (ground level, 2 and $4 \mathrm{~m}$ above ground). (D) Visual analysis map. 


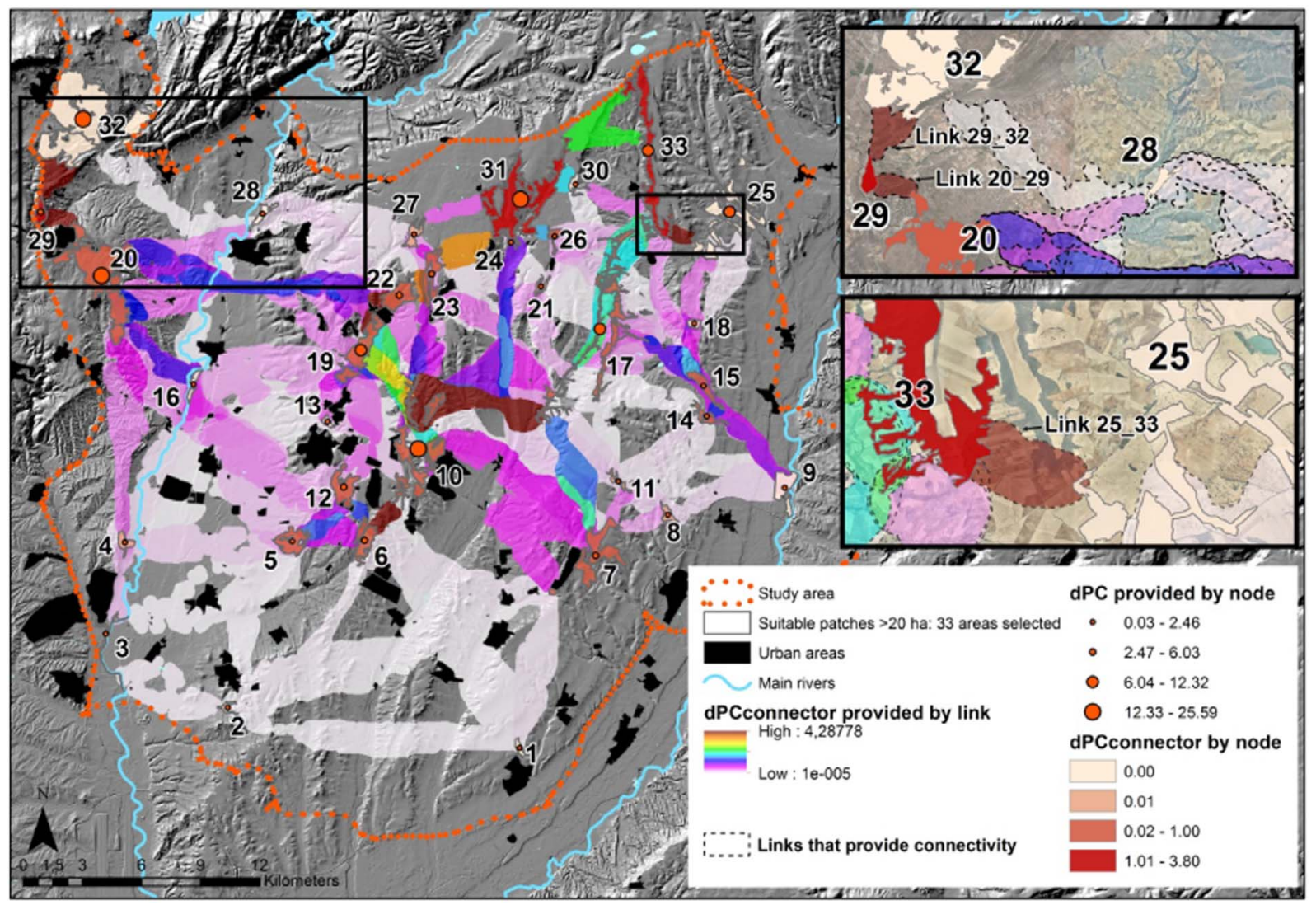

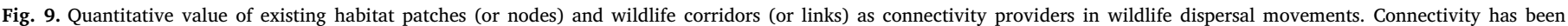
measured with the possibility of connectivity index (PC) developed by Saura and Pascual-Hortal (2007). Source: developed by Loro et al. (2015).

index values, which start to decline in these sections, as the road lies in a depression and is hidden from potential observers located in the surroundings. In contrast, $C V$ index values are high in section 17 because the road is easy to see by observers; however all the other partial indexes decrease, and the global index $I A_{k m}$ thus also decreases. $L A E_{k m}$ index showed that 6 of the 33 wildlife corridors were completely intersected by the new infrastructure (sections 21, 23, 30 and 32) but only one had certain importance for the landscape ecological connectivity $\left(6 \%\right.$ of $\overline{C_{k}}$ ). In parallel with the road's impact on wildlife corridors, four wildlife forest patch habitats suffered a direct reduction in connectivity due to loss of area caused by the new highway (with maximum values of $12.55 \%$ ).

Corrective measures such as designing wildlife passages, planting shrubs and hydro-seeding were also prioritized at a local scale (see Fig. 10-B,C and D). 96\% of the pixels in the cuttings and embankments evaluated (13,465 ha) obtained a very low priority, and only $3 \%$ (417 ha) obtained a low priority for the application of corrective measures. In contrast, $1 \%$ of highway slope pixels obtained priority values of over $50 \%$. Although this percentage is small, it represents a surface area of 55 ha to be planted.

Important differences were found in the landscape views observed by potential highway users travelling through this infrastructure or SHS (see Section 2.1.3), depending on the lane direction (left or right,) and search radius defined in the visibility analysis (Fig. 14 and Fig. 15). Thus $L Q_{p}$ values observed by users follow similar trends for right and left lanes for a $600 \mathrm{~m}$ search radius, although differences were found for a $1500 \mathrm{~m}$ search radius for each one-kilometer section, for example in the 42-45 km range (see Fig. 11-B). The combination of the results for 600 and $1500 \mathrm{~m}$ for both directions produces kilometer sections with higher values in the 23-28 range and the 39-51 range (Fig. 15).

\section{Discussion and conclusions}

The results of this research confirm the reliability of our GIS methodology for preventing visual impacts for potential observers in the surroundings or on a new highway, and ecological impacts.

The use of isocost bands of less cumulative impact -as an alternative to $L C P A$ - offers more realistic corridors for road planners as it considers several branches of similar cost and takes account of infrastructure width, which may help avoid bottlenecks. Previously, the Principal Components Analysis (PCA) was helpful for removing selected factors with redundant information (or potential collinearity) before combining them to build the cost matrix.

Although isocost bands were useful for locating the optimal layout in most of the study area, AASHTO geometric design limitations -curve radius, length of straight road stretches and profile slope- traced with AutoCAD Civil 3D prevented some sections from following these isocost bands. $L C P A$ and related algorithms -such as the algorithm applied to calculate isocost bands- produced solutions that are only minor perturbations of the optimal path. However although they may serve to trace the final route layout, they cannot be used in the public participation process in the Environmental Impact Assessment, where a wide variety of spatial configurations must be considered in the analysis of alternatives (Scaparra et al., 2014).The use of LiDAR introduces a significant novelty for preventing landscape impacts: the detailed recording of physical and ecological aspects for the creation of high-resolution thematic map sources. Beyond the traditional contour maps used in baseline analyses in environmental impact studies, LiDAR technology provides elevation data with a high density and accuracy required by contemporary geomorphometric analysis. This allows landscape parameters such as shape and diversity of terrain curvature to be calculated in small pixels for large-area inventories (Gessler et al., 2009), leading to an earlier identification of the optimal landforms for 


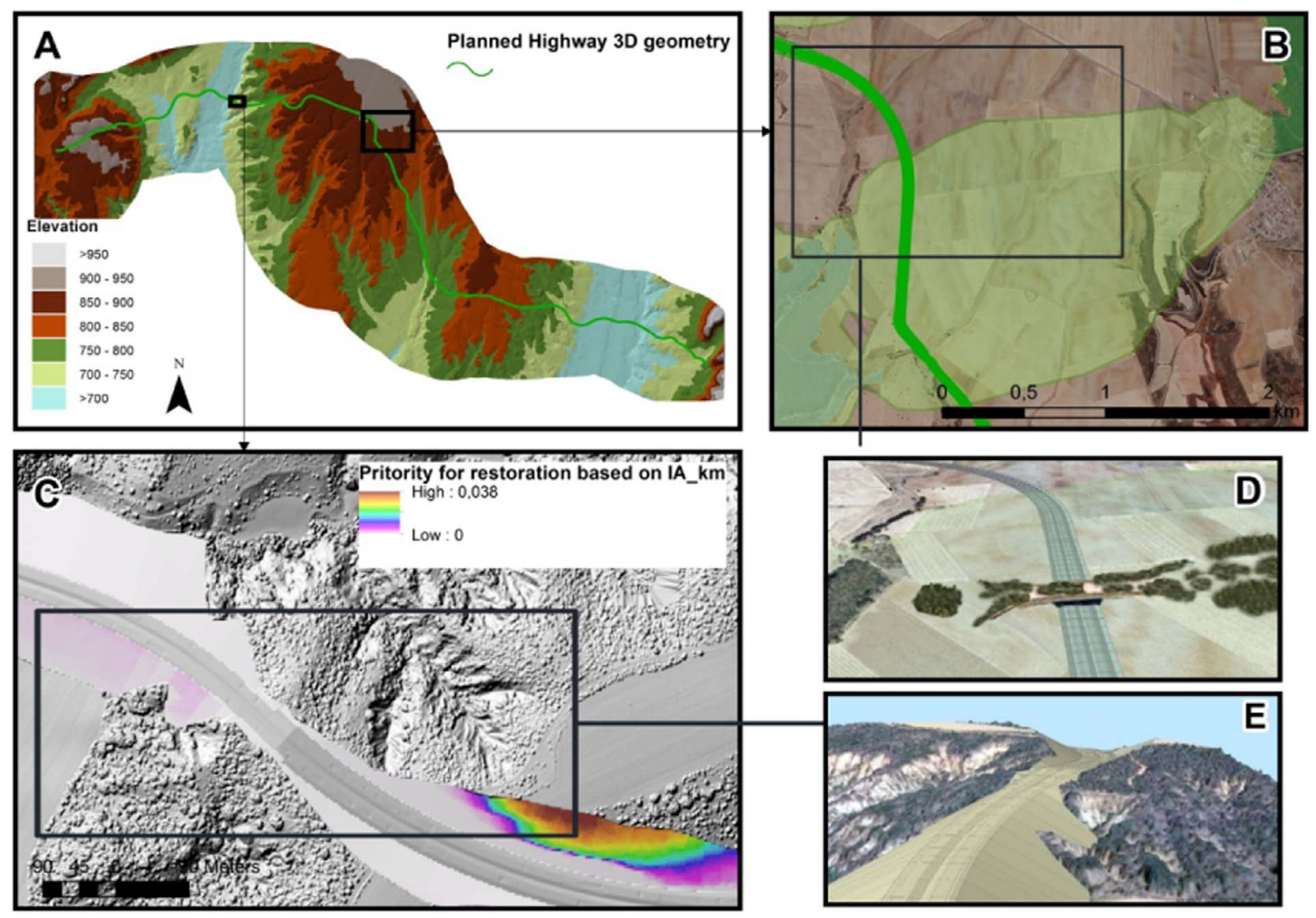

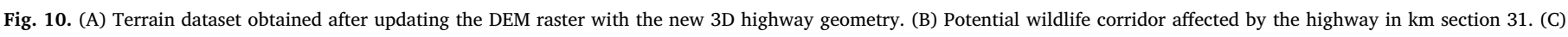

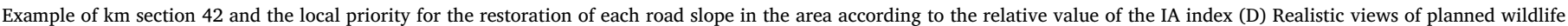
passages in section 31. (E) Realistic view of embankments in section 42.

hosting the highway. The visual impact on the landscape can thus be actively reduced in the design phase, and can serve to prevent impacts. Although LiDAR is a powerful information source, in addition to extracting thematic information by filtering based on standardized class code and return values, other post-processing was necessary. In this sense, proposed BDL model was useful and it is easily replicable by GIS users to reduce the complexity of the entire multipoint cloud by extracting meaningful subsets or a set of feature points.

Likewise, more complex models for generating DSMs can be found in the literature to extract object-based classification from LiDAR pulse return and remote sensing data such as tree species (Sasaki et al., 2012), roof details of buildings (Demir and Baltsavias, 2012) and geomorphology (Pfeifer et al., 2014). The LiDAR dataset had greater detail ( $0.15 \mathrm{~m}$ pixel size) in these studies than in our source $(0.25 \mathrm{~m})$, and field surveys were done due to the smaller study areas. In parallel, multivariate remote sensing techniques such as maximum likelihood supervised classification were applied by collecting sampling points containing objects detected in orthophotos as inputs to help in defining building footprints.

In the case of geomorphological analysis, existing geomorphological classifications of DEM can be adapted to the recommendations in the tracing guidelines. We extracted 10 landform elements out of 15 in the Schmidt and Hewitt (2004) classification (see Fig. 4). The reduction in the number of elements probably occurred due to our modification of the original threshold values in order to adjust to highway design standards and tracing recommendations. Others landform element classifications could be applied (e.g. MacMillan et al., 2000, 2004; MacMillan and Shary, 2009) as well as the selection of geometrical LSP (curvatures) using a different combination of the local polynomial calculated following Evans (1979). However we were unable to use the $V R M$ index to locate appropriate landforms to host the highway due to the tracing recommendations contained in the guidelines. Although the ruggedness index $V R M$ was a good descriptor of $L Q_{p}$ (see Fig. 6-B), other indexes such as curvature and slope identified landform elements more effectively. Apart from slope (local scale parameter) and elevation contours as constraining criteria in road planning, we found that semisupervised models for landform elements (local scale) and types (regional scale) can be fitted to tracing recommendations. The output raster format also allowed us to use MCE and accumulative cost functions to optimize the layout (see Fig. 12).

Jessel (2006) defines several challenges when studying the physical elements of landscape, such as: (c1) the availability of data from landuse mapping on perception-forming items such as small structures and general spatial structures; (c2) the relation between individual types of utilization and structural elements; and (c3) the general spatial perceptional references in transitional zones where the boundaries are unclear. In our approach, the analysis of the physical landscape aspects revealed that individual landscape components were profusely described according to design shapes and proportions (c1) thanks to the detailed database of landscape attributes produced from LiDAR. This allowed us to develop a more complex $L Q_{p}$ model than Vizzari's (2011), but maintaining the use of $K D E$ density as a tool to assess the overall perception of areas with a similar appearance (c2 and c3). Thus individual landscape components were assessed according to their local quantitative values $(L Q V)$, including degree of movement of river water, ruggedness of landforms, vegetation canopy cover fraction (CC) and tree height (Fig. 5), building height (highest present in the scene) and footprint (Fig. 7), among others (Table 4). Our study included an important simplification in which no anthropic constructions were considered as elements that could increase the $L Q_{p}$; this was due to the availability of non-cartographic data with enough detailed information on the study area. The literature contains some good examples of 


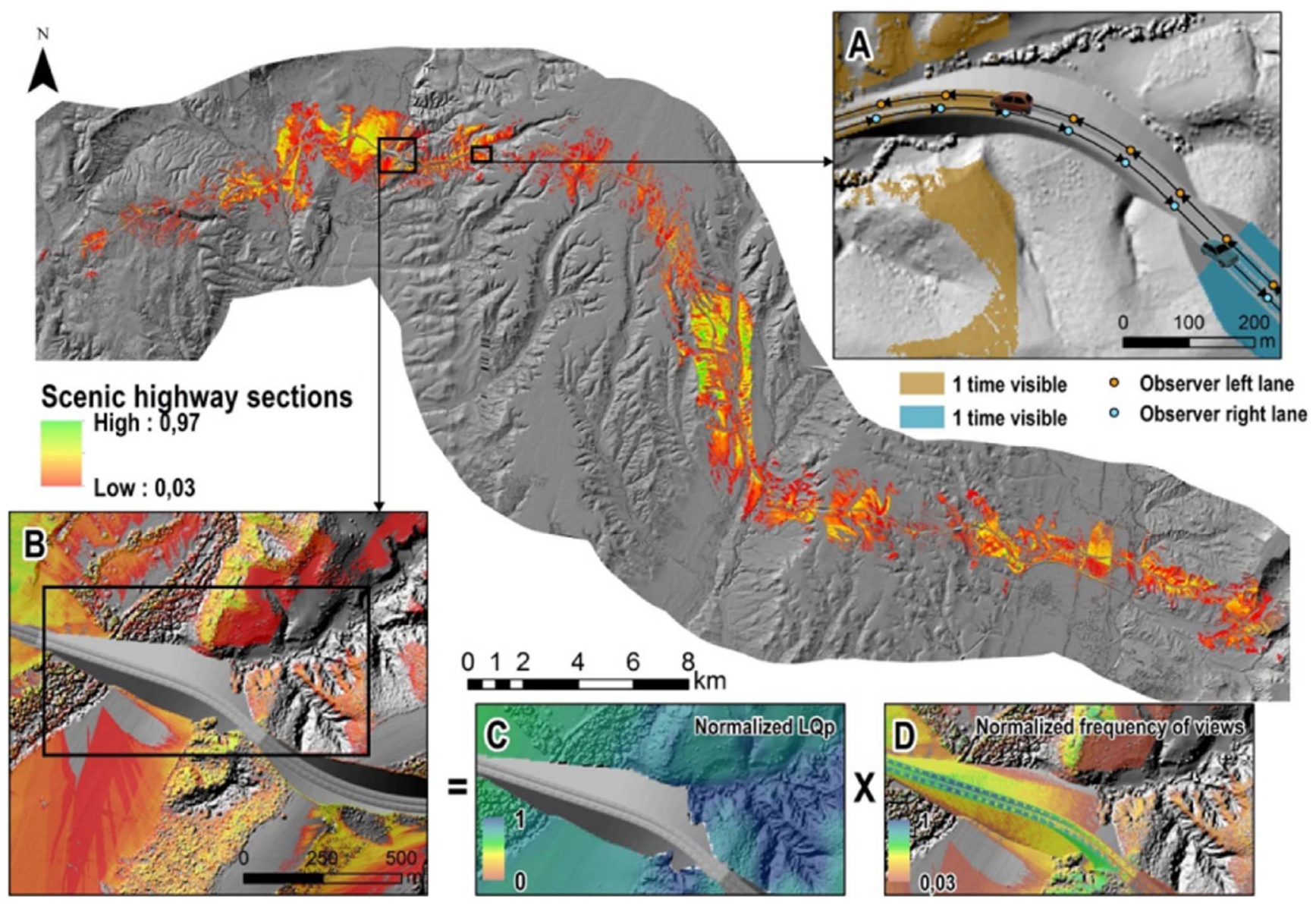

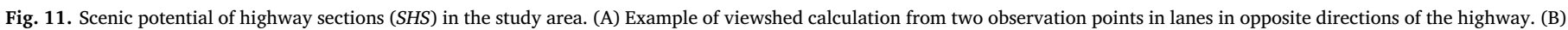

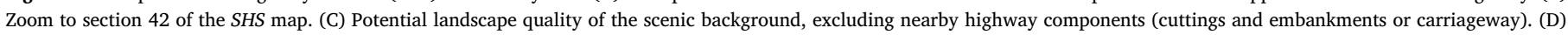
Cumulative viewshed (CV) map or frequency of views by users every $100 \mathrm{~m}$.

increases or decreases in the $L Q_{p}$ when detailed physical attributes of construction such as textures, colour or forms are available or obtained from field studies (Cano et al., 2013, Cañas et al., 2009). Also, visual analysis performed after the inclusion of the new highway geometry in the DSM improved the realism in the calculation of the cumulative views parameter due to the effects of local screening elements such as trees or buildings, or highway sections in depressions, where it was completely hidden from observers sited in the surroundings (Fig. 11-A) and in the highway surroundings (Fig. 11-D). Also, different heights $\left(C V_{o}, C V_{2}\right.$ and $\left.C V_{4}\right)$ and road layout orientation were corrected based on the variation of horizontal (car trajectory and its azimuth) and vertical angles. The influence of distance from surrounding potential observers was included through the project visibility $(V P)$ index.

The inclusion of the new highway 3D geometry in the DSM also allowed us to compute visual impact indicators $I A_{k m}, L A E_{k m}$ and $S H S$ and quantify the overall impacts of highway sections at a global scale, as well as locating detailed areas of embankments to be restored or where wildlife passages could be built. The SHS index identified which zones of cuttings and embankments should be planted and hydro-seeded due to high rates of $C V$ and $L Q_{p}$ (see Fig. 10). On the basis of $\mathrm{DSM}_{\mathrm{h}}$ (Fig. 11 and Fig. 12), screening plantation areas can also be planned in a realistic way according to the visual intrusion of the new project in the surroundings and by improving road lane legibility and avoiding glare for drivers (see Chalkias et al., 2013). Herb species can be selected for hydro-seeding based on the microconditions of each embankment using slope or wet ground indexes to estimate soil moisture or potential erosion (Jelaska, 2009). Besides the $L A E_{k m}$ index clearly highlights two areas (Sections 22 and 33) where a wildlife passage should be built to maintain fauna dispersal movements (Fig. 11).
Within the framework of landscape analysis and environmental impact assessment, the proposed methodology could effectively support self-producing thematic maps from LiDAR data. This enhances the analysis of landscape in a detailed scale planning (1:5 K), improves the location of highway sections with the lowest rates of cumulative views for observers outside the infrastructure, and allows the identification of the optimal landforms for hosting the highway with the minimum visual impact on the landscape. Visual and ecological impacts were located, thus enabling their restoration. The inclusion of 3D geometry allowed the creation of 3D scenes which are in great demand by stakeholders in environmental impact assessment processes and at the public participation stage (Paar, 2006). The combined used of LiDAR and geomorphology can help decision-makers assess which road layouts produce higher impacts, provide insights into value judgments, and define which corrective landscaping measures should be applied, and where. Following this research line, focus groups made up of residents and occasional visitors could be asked to measure their perception of the landscape before and after the inclusion of the new highway in the scene using photorealistic rendering methods as propose Ghadirian and Bishop (2008).

Our research focuses on the GIS components of the GIS-MCA methods, especially the development of geographical data models and the spatial dimension of the evaluation criteria reviewed by Malczewski (2006). Other MCA method approaches may complement the proposed methodology, including those based on the nature of the evaluation criteria, the number of individuals involved in the decision-making process and the nature of uncertainties, in order to improve the spatial definition of decision alternatives for new routes. This study of landscape can help fulfilling the requirements of European Landscape 


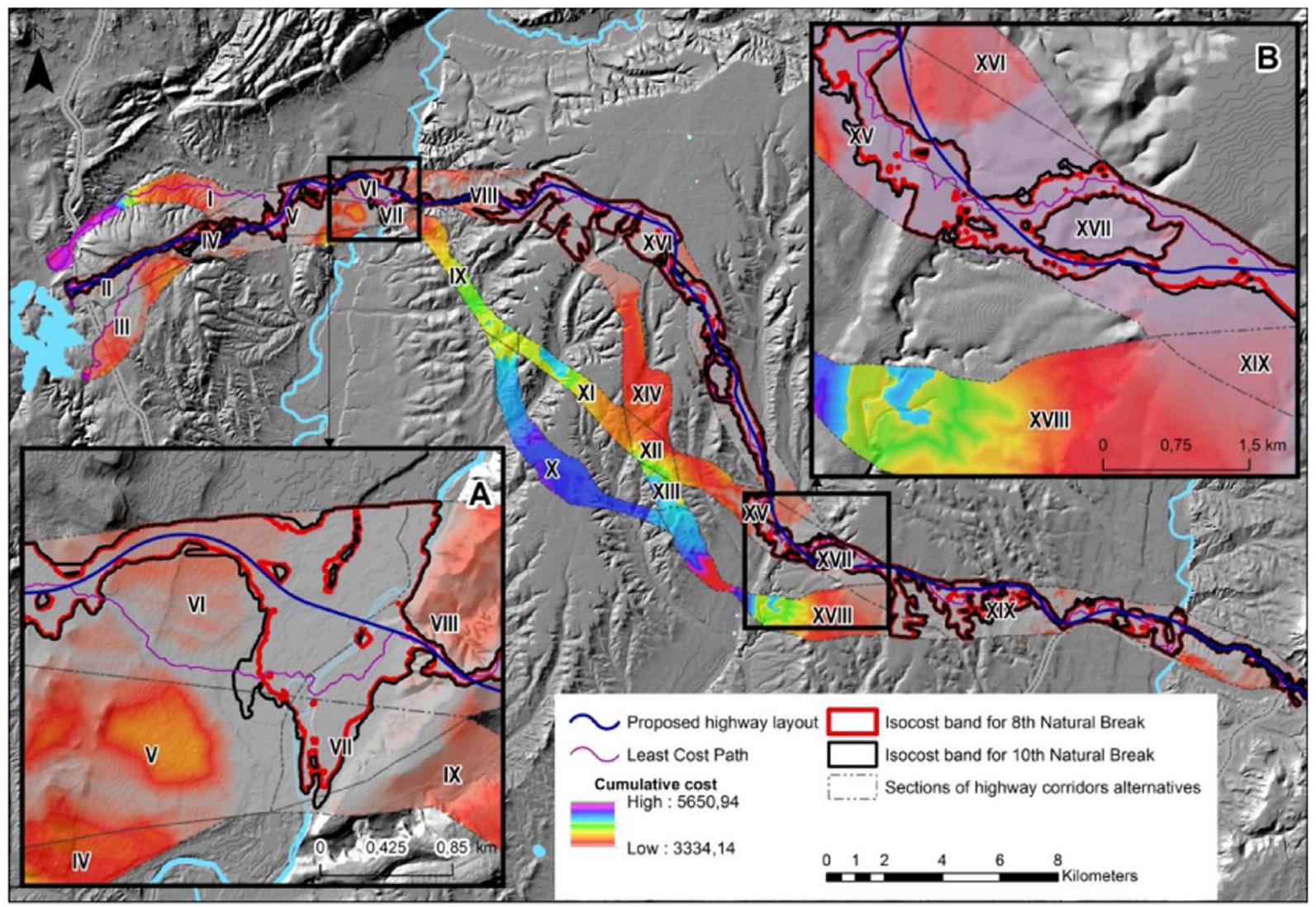

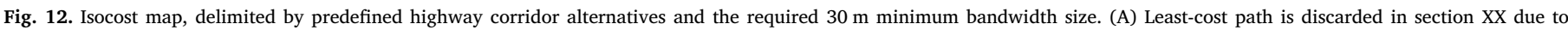
bottlenecks. (B) Corridor section where layout was outside the isocost band due to limitations design.

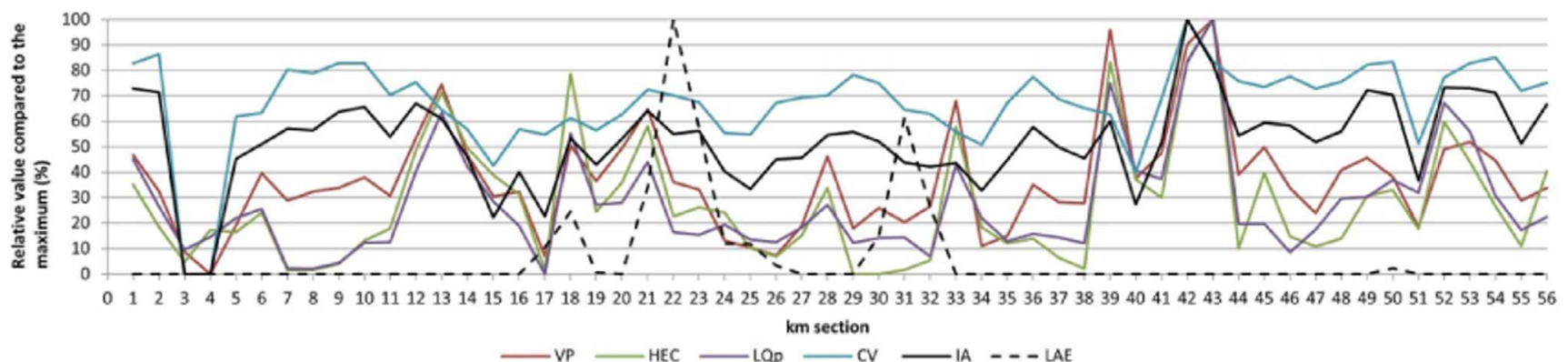

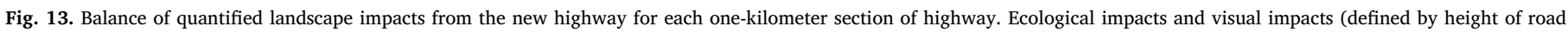
slopes, cumulative views from observers located in the new highway surroundings and landscape scenic quality) are shown, along with the combination of both.

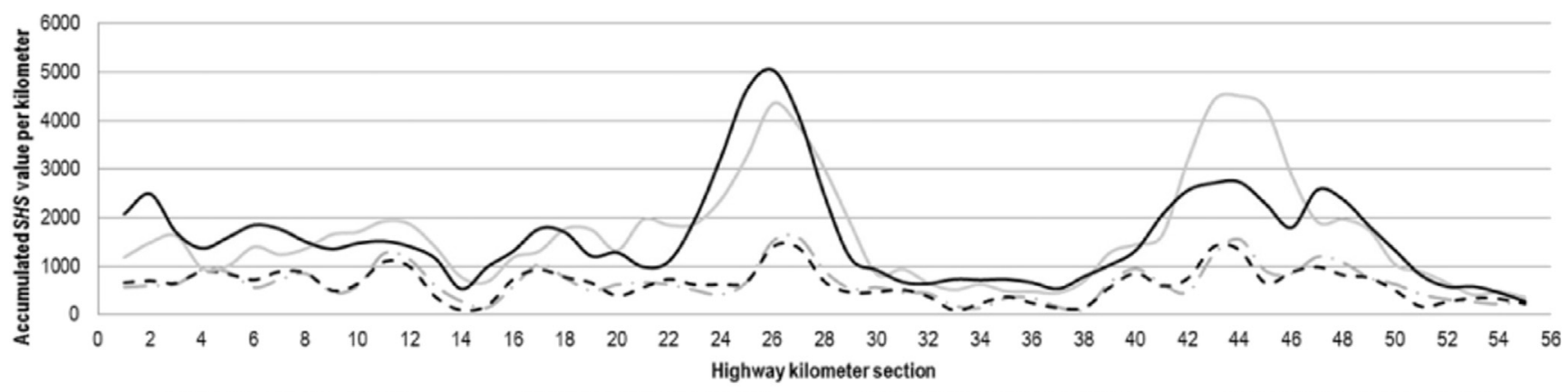

- - radius $600 \mathrm{~m}$, left lane direction _ - - radius $600 \mathrm{~m}$, right lane direction —— radius $1500 \mathrm{~m}$, left lane direction _ radius $1500 \mathrm{~m}$, right lane direction

Fig. 14. SHS index calculated for each lane direction (right and left) and search radius in the analysis (600 and $1500 \mathrm{~m})$. 


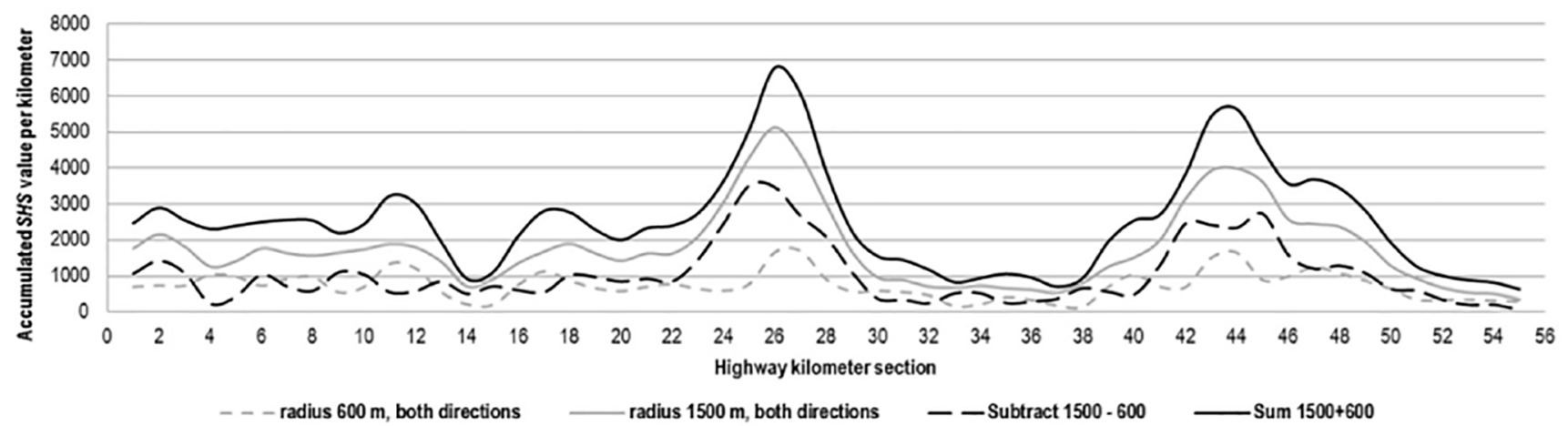

Fig. 15. SHS index calculated for each section for a different search radius in the analysis (600 and $1500 \mathrm{~m})$, aggregating the analysis of both lanes.

Convention (CE, 2000) and be a useful tool for civil engineers to improve the integration of new highways into the landscape.

\section{Acknowledgements}

This article is the summary of the final phase of the MILL project (TRA2010-18311. MILL: Path integration model of linear infrastructure in the landscape based on GIS), which is sponsored by the National R \& D \& i 2008-2011 CICYT Plan of the Spanish Ministry of Science and Innovation.

We would like to thank Ms. Prudence Brooke-Turner for her revision of the English manuscript.

\section{References}

AASHTO, 1991. A guide for Transportation Landscape and Environmental Design. (American Association of State Highway and Transportation Officials, Ed.). American Association of State Highway and Transportation Officialspp. 84.

AASHTO American Association of State Highway, 2004. A Policy on Geometric Design of High- Ways and Streets, 5th ed. American Association of State Highway and Transportation Officials, Washington DC.

Antonson, H., 2009. Bridging the gap between research and planning practice concerning landscape in Swedish infrastructural planning. Land Use Policy 26, 169-177. http:// dx.doi.org/10.1016/j.landusepol.2008.02.009.

Appleyard, D., Lynch, K., Myer, J.R., 1964. The View from the Road. The MIT Press, Cambridge, MA.

Arce, R., Ortega, E., Otero, I., 2010. Los sistemas de información geográfica aplicados a la evaluación ambiental en la planificación de las infraestructuras de transporte. In Ciudad y territorio. Estudios territoriales. 165-166. pp. 513-528 (ISSN: 1133-4762).

Atkinson, D.M., Deadman, P., Dudycha, D., Traynor, S., 2005. Multi-criteria evaluation and least cost path analysis for an arctic all-weather road. Appl. Geogr. 25 (4), 287-307. http://dx.doi.org/10.1016/j.apgeog.2005.08.001.

Bagli, S., Geneletti, D., Orsi, F., 2010. Routeing of power lines through least-cost path analysis and multicriteria evaluation to minimise environmental impacts. Environ. Impact Assess. Rev. 31 (3), 234-239. http://dx.doi.org/10.1016/j.eiar.2010.10.003.

Burrough, P.A., 1989. Fuzzy mathematical methods for soil survey and land evaluation. J. Soil Sci. 40 (3), 477-492. http://dx.doi.org/10.1111/j.1365-2389.1989.tb01290.x.

Cano, M., Garzon, E., Sanchez-Soto, P.J., 2013. Historic preservation, GIS, \& rural development: the case of Almería province, Spain. Appl. Geogr. 42, 34-47. http://dx. doi.org/10.1016/j.apgeog.2013.04.014.

Cañas, I., Ayuga, E., Ayuga, F., Canas, I., 2009. A contribution to the assessment of scenic quality of landscapes based on preferences expressed by the public. Land Use Policy 26 (4), 1173-1181. http://dx.doi.org/10.1016/j.landusepol.2009.02.007 ER.

Chalkias, C., Faka, A., Kalogeropoulos, K., 2013. Assessment of the direct sun-light on rural road network through solar radiation analysis using GIS. Open J. Appl. Sci. 03 (02), 224-231. http://dx.doi.org/10.4236/ojapps.2013.32030.

Chamberlain, B.C., Meitner, M.J., 2013. A route-based visibility analysis for landscape management. Landsc. Urban Plan. 111 (0), 13-24. http://dx.doi.org/10.1016/j. landurbplan.2012.12.004.

Childs, C., 2011. Terrain Datasets. The top 10 Reasons to use them. In: Pratt, M. (Ed.), ArcUser. Spring. Redlands, California, ESRI, pp. 40-45.

CE. Council of Europe, 2000. European Landscape Convention. In: Florence: Council of Europe (European Treaty Series No. 176).

Demir, N., Baltsavias, E., 2012. Automated modeling of 3D building roofs using image and LiDAR data. ISPRS Ann. Photogramm. Rem. Sens. Spatial Inf. Sci I-4, 35-40.

Dijkstra, E.W., 1959. A note on two problems in connexion with graphs. Numeriske Mathematik 1, 269-271. http://dx.doi.org/10.1007/BF01386390.

Dikau, R., 1989. The application of a digital relief model to landform analysis. In: Raper, J.F. (Ed.), Three Dimensional Applications in Geographical Information Systems. Taylor \& Francis, London, pp. 51-77.

Dramstad, W.E., et al., 2006. Relationships between visual landscape preferences and map-based indicators of landscape structure. Landsc. Urban Plan. 78 (4), 465-474. http://dx.doi.org/10.1016/j.landurbplan.2005.12.006.

Español, I., Álvarez, D., Fernández, D., González, C., 2008. La carretera en el paisaje. Criterios para su planificación, trazado y proyecto (p. 451). Consejería de Obras Públicas y Transportes. Junta de Andalucía, Sevilla.

Evans, I.S., 1979. An Integrated System of Terrain Analysis and Slope Mapping. University of Durham, England.

Fry, G., Tveit, M.S., Ode, Å., Velarde, M.D., 2009. The ecology of visual landscapes: exploring the conceptual common ground of visual and ecological landscape indicators. Ecol. Indic. 9 (5), 933-947. http://dx.doi.org/10.1016/j.ecolind.2008.11.008.

Gessler, P., Pike, R., MacMillan, R., Hengl, T., Reuter, H., 2009. The future of Geomorphometry. Dev. Soil Sci. 33 (8), 637-652. http://dx.doi.org/10.1016/S01662481(08)00028-7.

Ghadirian, P., Bishop, I.D., 2008. Integration of augmented reality and GIS: a new approach to realistic landscape visualisation. Landsc. Urban Plan. 86, 226-232. http:// dx.doi.org/10.1016/j.landurbplan.2008.03.004.

Glaría, G., Ceñal, M.Á., 1993. The impact of roads on landscape and corrective measures. Detailed study. Inf. Constr. 45 (425-426), 19-26. http://dx.doi.org/10.3989/ic. 1993.v45.i425-426.1180.

González, E., Moreno, E., Cabello, F., Alvarez, E., 2012. Methodology for drafting least environmental cost railway corridors. Practical case study: high speed rail route Huelva (Spain) - Faro (Portugal). Inf. Constr. 64 (527), 415-423. http://dx.doi.org/ 10.3989/ic.11.029.

Gobster, P.H., Nassauer, J.I., Daniel, T.C., Fry, G., 2007. The shared landscape:what does aesthetics have to do with ecology? Landsc. Ecol. 22, 959-972. http://dx.doi.org/10. 1007/s10980-007-9110-x.

Iuell, B., Bekker, G.J., Cuperus, R., Dufek, J., Fry, G., Hicks, C., Wandall, B., 2003. Wildlife and Traffic: a European Handbook for Identifying Conflicts and Designing Solutions. In: COST 341 - Habitat Fragmentation due to Transportation Infrastructure.

Jelaska, S., 2009. Vegetation mapping applications. Dev. Soil Sci. 33 (08), 481-496. http://dx.doi.org/10.1016/S0166-2481(08)00021-4.

Jenks, G.F., 1967. The data model concept in statistical mapping. In: International Yearbook of Cartography. 7. pp. 186-190.

Jenness, 2011. DEM Surface Tools. 2.1. Jenness Enterprisespp. 292.

Jenness, J., Brost, B., Beier, P., 2011. Land Facet Corridor Designer. USDA Forest Service Rocky Mountain Research Station, Arizona.

Jessel, B., 2006. Elements, characteristics and character - information functions of landscapes in terms of indicators. Ecol. Indic. 6 (1), 153-167. http://dx.doi.org/10. 1016/j.ecolind.2005.08.009.

Liu, X., 2008. Airborne LiDAR for DEM generation: some critical issues. Prog. Phys. Geogr. 32 (1), 31-49. http://dx.doi.org/10.1177/0309133308089496.

Llausàs, A., Nogué, J., 2012. Indicators of landscape fragmentation: the case for combining ecological indices and the perceptive approach. Ecol. Indic. 15 (1), 85-91. http://dx.doi.org/10.1016/j.ecolind.2011.08.016.

Loro, M., Arce, R.M., Ortega, E., Martín, B., 2014. Road-corridor planning in the EIA procedure in Spain. A review of case studies. Environ. Impact Assess. Rev. 44 (0), 11-21. http://dx.doi.org/10.1016/j.eiar.2013.08.005.

Loro, M., Ortega, E., Arce, R.M., Geneletti, D., 2015. Ecological connectivity analysis to reduce the barrier effect of roads. An innovative graph-theory approach to define wildlife corridors with multiple paths and without bottlenecks. Landsc. Urban Plan. 239 (0), 149-162. http://dx.doi.org/10.1016/j.landurbplan.2015.03.006.

MacMillan, R.A., Pettapiece, W., Nolan, S.C., Goddard, T.W., 2000. A generic procedure for automatically segmenting landforms into landform elements using DEMs, heuristic rules and fuzzy logic. Fuzzy Sets Syst. 113 (1), 81-109. http://dx.doi.org/10. 1016/S0165-0114(99)00014-7.

MacMillan, R.A., Jones, R.K., McNabb, D.H., 2004. Defining a hierarchy of spatial entities for environmental analysis and modeling using digital elevation models (DEMs). Comput. Environ. Urban. Syst. 28 (3), 175-200. http://dx.doi.org/10.1016/S01989715(03)00019-X.

MacMillan, R.A., Shary, P.A., 2009. Landforms and landform elements in Geomorphometry. Dev. Soil Sci. 33 (2001), 227-254. http://dx.doi.org/10.1016/ S0166-2481(08)00009-3.

Malczewski, J., 1999. GIS and Multicriteria Decision Analysis (MCDA). John Wiley \& Sons, Inc., New York.

Malczewski, J., 2006. GIS-based multicriteria decision analysis: a survey of the literature. Int. J. Geogr. Inf. Sci. 20 (7), 703-726. http://dx.doi.org/10.1080/ 
13658810600661508

Mark, A., Marek, P.E., 2009. Landscape And Aesthetics Design Manual. Retrieved from. http://onlinemanuals.txdot.gov/txdotmanuals/lad/topography_and_grading.htm.

Martín, B., Ortega, E., Otero, I., Arce, R.M., 2017. Landscape character assessment with GIS using map-based indicators and photographs in the relationship between landscape and roads. J. Environ. Manag. 180, 324-334.

Ministerio de Fomento, 2005. SIOSE Project (Spaniard Land Use and Land Cover Information System). Retrieved from. http://www.siose.es/siose/.

Ministerio de Fomento - Esteyco, 1999. Guía Metodológica para la inclusión de proyectos ambientales en los proyectos de carreteras. Dirección General de Carreteras, Subdirección General de proyectos, Madrid.

Oberholzer, B., 2005. Guideline for involving visual and aesthetic specialists in EIA processes. CSIR Report No ENV-S-C 2005 053. Edition 1. Cape Town Retrieved from. http://www.westerncape.gov.za/text/2005/4/deadp_visual_guideline_draft_ 15april05.pdf.

Olaya, V., 2009. Basic land-surface Parametres. Dev. Soil Sci. 33, 141-169. http://dx.doi. org/10.1016/S0166-2481(08)00006-8.

Ortega, E., Martín, B., Gonzalez, E., Moreno, E., 2016. A contribution for the evaluation of the territorial impact of transport infrastructures in the early stages of the EIA: application to the Huelva (Spain)-Faro (Portugal) rail link. J. Environ. Plan. Manag. 59 (2), 302-319. http://dx.doi.org/10.1080/09640568.2015.1009628.

Paar, P., 2006. Landscape visualizations: applications and requirements of 3D visualization software for environmental planning. Comput. Environ. Urban. Syst. 30 (6), 815-839. http://dx.doi.org/10.1016/j.compenvurbsys.2005.07.002.

Pfeifer, N., Mandlburger, G., Otepka, J., Karel, W., 2014. OPALS - a framework for airborne laser scanning data analysis. Comput. Environ. Urban. Syst. 45 (0), 125-136. http://dx.doi.org/10.1016/j.compenvurbsys.2013.11.002.

Pike, R.J., Evans, I.S., Hengl, T., 2009. Geomorphometry: A Brief Guide. In: Developments in Soil Science. Geomorphometry Concepts, Software, Applications. Elsevier, pp. 3-30. http://dx.doi.org/10.1016/S0166-2481(08)00001-9.

Russo, P., Carullo, L., Riguccio, L., Tomaselli, G., 2011. Identification of landscapes for drafting Natura 2000 network management plans: a case study in Sicily. Landsc. Urban Plan. 101 (3), 228-243. http://dx.doi.org/10.1016/j.landurbplan.2011.02. 028 .

Sappington, J., Longshore, K.M., Thompson, D.B., 2007. Quantifying landscape ruggedness for animal habitat analysis: a case study using bighorn sheep in the Mojave Desert. J. Wildl. Manag. 71 (5), 1419-1426.

Sasaki, T., Imanishi, J., Ioki, K., Morimoto, Y., Kitada, K., 2012. Object-based classification of land cover and tree species by integrating airborne LiDAR and high spatial resolution imagery data. Landsc. Ecol. Eng. 8 (2), 157-171. http://dx.doi.org/10 1007/s11355-011-0158-Z.

Saura, S., Pascual-Hortal, L., 2007. A new habitat availability index to integrate connectivity in landscape conservation planning: comparison with existing indices and application to a case study. Landsc. Urban Plan. 83 (2-3), 91-103. http://dx.doi.org/ 10.1016/j.landurbplan.2007.03.005.

Saura, S., Rubio, L., 2010. A common currency for the different ways in which patches and links can contribute to habitat availability and connectivity in the landscape. Ecography 33, 523-537. http://dx.doi.org/10.1111/j.1600-0587.2009.05760.x.

Scaparra, M., Church, R., Medrano, F.A., 2014. Corridor location: the multi-gateway shortest path model. J. Geogr. Syst. 1-23. http://dx.doi.org/10.1007/s10109-0140197-8.

Schmidt, J., Hewitt, A., 2004. Fuzzy land element classification from DTMs based on geometry and terrain position. Geoderma 121 (3-4), 243-256. http://dx.doi.org/10. 1016/j.geoderma.2003.10.008.

Shary, P.A., 1995. Land surface in gravity points classification by a complete system of curvatures. Math. Geol. 27 (3), 373-390.

Stucky, J.L.D., Lee, J., Stucky, D., 1998. On applying viewshed analysis for determining least-cost paths on digital elevation models. Int. J. Geogr. Inf. Sci. 12 (8), 891-905.

Tveit, M., Ode Sang, A., 2014. Landscape assessment in metropolitan areas - developing a visual indicator-based approach. SPOOL 1 (1). http://dx.doi.org/10.7480/spool 2013.1.641.

The Scottish Highway Agency, 1992. Section 1. New roads. Landform and Aligments. In: Design Manual for Roads and Bridges. Volume 10. HA 55/92. (First edit., p. 39). Welsh Assembly Government and The Department for Regional Development Northern Ireland, Edimburg.

Zealand, Transit New, 2006. Guidelines for Highway Landscaping. NZ Transport Agency, New Zealand.

Valladares, F., Balaguer, L., Mola, I., Escudero, A., Alfaya, V., 2011. Restauración ecológica de áreas afectadas por infraestructuras de transporte. Bases científicas para soluciones técnicas. (p. 164). Fundación Biodiversidad, Madrid.

Van Eetvelde, V., Antrop, M., 2009. Indicators for assessing changing landscape character of cultural landscapes in Flanders (Belgium). Land Use Policy 26, 901-910. http://dx doi.org/10.1016/j.landusepol.2008.11.001.

Vizzari, M., 2011. Spatial modelling of potential landscape quality. Appl. Geogr. 31 (1), 108-118. http://dx.doi.org/10.1016/j.apgeog.2010.03.001.

Weiss, A.D., 2000. Topographic position and landforms analysis. In: Poster Presentation, ESRI Users Conference. San Diego, CA.

Wood, J., 1996. The geomorphological characterisation of digital elevation models. University of Lancaster, (UK).

Wu, Y., Bishop, I., Hossain, H., Sposito, V., 2006. Using GIS in landscape visual quality assessment. Applied GIS 2 (3), 18.1-18.20. http://dx.doi.org/10.2104/ag060018.

Manuel Loro, is a researcher at the Department of Transport and Territory in the Civil Engineering School of the Technical University of Madrid (UPM).He is also member of TRANSYT (Transport Research Centre-UPM). His research topic is focused on Environmental Impact Assessment and GIS planning. He focuses his research on GIS applications to reduce environmental impacts, especially associated to new roads building.

Rosa M. Arce is an associate professor at the Department of Transport and Territory in the Civil Engineering School of the Technical University of Madrid (UPM). She is also member of TRANSYT (Transport Research Centre-UPM). She has over 25 years of EIA experience as a project manager, and as a special-its advisor-peer reviewer in such areas as impact prediction and interpretation methodology, alternatives evaluation and the integration of sustainability in decision making. She has wide experience in applied EIA practice and research, taught EIA at the graduate and undergraduate levels, and published widely in the field.

Emilio Ortega, is an assistant professor of GIS at the Department of Forestry and Environmental Engineering and Management in the Forestry Engineering School of the Technical University of Madrid (UPM). He is also member of TRANSYT (Transport Research Centre-UPM). His research topic is focused on territorial transport planning and strategic environmental assessment. 